\title{
Microphysical simulations of new particle formation in the upper troposphere and lower stratosphere
}

\author{
J. M. English ${ }^{1}$, O. B. Toon ${ }^{1}$, M. J. Mills ${ }^{2}$, and F. Yu ${ }^{3}$ \\ ${ }^{1}$ Laboratory for Atmospheric and Space Physics, Department of Atmospheric and Oceanic Sciences, University of Colorado, \\ Boulder, CO, USA \\ ${ }^{2}$ NCAR Earth System Laboratory, National Center for Atmospheric Research, Boulder, CO, USA \\ ${ }^{3}$ Atmospheric Sciences Research Center, State University of New York, Albany, NY, USA
}

Received: 2 April 2011 - Published in Atmos. Chem. Phys. Discuss.: 20 April 2011

Revised: 23 July 2011 - Accepted: 26 August 2011 - Published: 9 September 2011

\begin{abstract}
Using a three-dimensional general circulation model with sulfur chemistry and sectional aerosol microphysics (WACCM/CARMA), we studied aerosol formation and microphysics in the upper troposphere and lower stratosphere (UTLS) as well as the middle and upper stratosphere based on three nucleation schemes (two binary homogeneous schemes and an ion-mediated scheme related to one of the binary schemes). Simulations suggest that ion-mediated nucleation rates in the UTLS are $25 \%$ higher than its related binary scheme, but that the rates predicted by the two binary schemes vary by two orders of magnitude. None of the nucleation schemes is superior at matching the limited observations available at the smallest sizes. However, it is found that coagulation, not nucleation, controls number concentration at sizes greater than approximately $10 \mathrm{~nm}$. Therefore, based on this study, processes relevant to atmospheric chemistry and radiative forcing in the UTLS are not sensitive to the choice of nucleation schemes. The dominance of coagulation over other microphysical processes in the UTLS is consistent with other recent work using microphysical models. Simulations using all three nucleation schemes compare reasonably well to observations of size distributions, number concentration across latitude, and vertical profiles of particle mixing ratio in the UTLS. Interestingly, we find that we need to include Van der Waals forces in our coagulation scheme to match the UTLS aerosol concentrations. We conclude that this model can reasonably represent sulfate microphysical processes in the UTLS, and that the properties of particles at atmospherically relevant sizes appear to be insensitive to
\end{abstract}

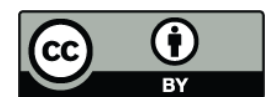

Correspondence to: J. English

(englishj@colorado.edu) the details of the nucleation scheme. We also suggest that micrometeorites, which are not included in this model, dominate the aerosol properties in the upper stratosphere above about $30 \mathrm{~km}$.

\section{Introduction}

The tropical upper troposphere is known to be a net source region of new particles (e.g. Brock et al., 1995; Clarke and Kapustin, 2002). These particles may cross the tropopause and accelerate stratospheric ozone destruction via heterogeneous chemistry (Hofmann and Solomon, 1989), impact climate by modifying cirrus cloud properties in the upper troposphere (Jensen et al., 1996), and possibly descend to the marine boundary layer and act as cloud condensation nuclei (CCN) there (Clark, 1993). The UTLS region does not have a standard spatial definition, but we generally refer to the region between 50 and $500 \mathrm{hPa}$. Climate geoengineering schemes are receiving increased attention in recent years especially those related to UTLS aerosols such as stratospheric sulfur injection (e.g. Crutzen, 2006; Robock et al., 2008; Heckendorn et al., 2009) and cirrus cloud modification (e.g. Rasch et al., 2008). However, mechanisms of UTLS new particle formation (NPF) continue to be poorly understood.

Classical nucleation theory suggests binary homogeneous nucleation (BHN) of sulfuric acid and water is favored in the UTLS due to cold temperatures and availability of supersaturated sulfuric acid and water (Brock et al., 1995). Other nucleation processes are also possible but are generally associated with nucleation at warmer temperatures or closer to surface sources, including ternary nucleation mediated by ammonia (Coffman and Hegg, 1995) or by organic molecules

Published by Copernicus Publications on behalf of the European Geosciences Union. 


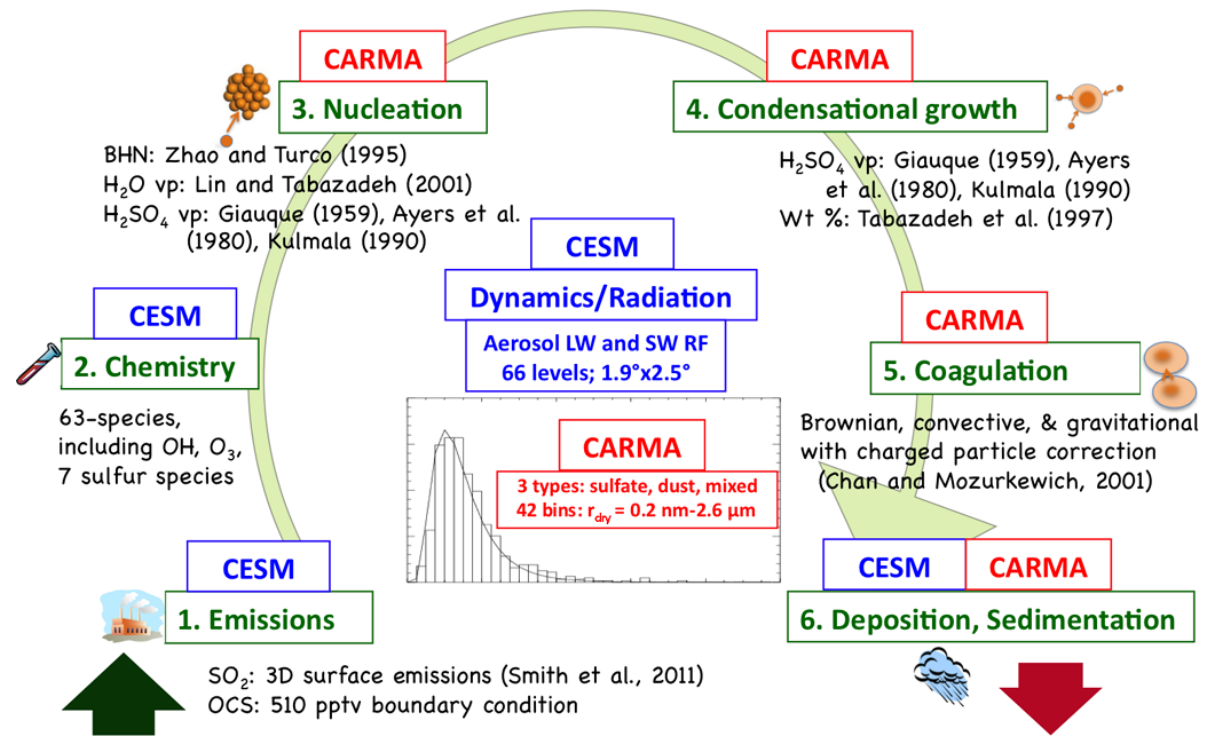

Fig. 1. Diagram of the WACCM/CARMA Model. WACCM simulates emissions, chemistry, dynamics and wet deposition. CARMA simulates nucleation, condensational growth, coagulation, and sedimentation.

(Zhang et al., 2004). Ion-mediated nucleation (IMN) of sulfuric acid and water has received increased attention in recent years as a possible link between solar activity and climate (Yu and Turco, 2001; Lovejoy et al., 2004). Ions produced by cosmic rays entering earth's atmosphere may stabilize molecular clusters, increasing the formation rate and number of new particles. As these ions are produced in much of the earth's atmosphere (Usoskin et al., 2009), they can potentially influence nucleation rates in any region. While numerous modeling and observational studies have investigated IMN in the lower troposphere (e.g. Yu and Turco 2001, 2011; Lovejoy et al., 2004; Eisele et al., 2006), study of the UTLS region is more limited. Kanawade and Tripathi (2006) calculated IMN with a sectional aerosol model and found agreement with UTLS observations, but did not compare with BHN simulations. Pierce and Adams (2009) and SnowKropla et al. (2011) calculated changes in IMN from solar cycle changes using a sectional model and found the IMN contribution to cloud condensation nuclei to be two orders of magnitude too small to account for observed changes in cloud properties. Yu and Luo (2009) calculated IMN with a sectional microphysical aerosol model and found reasonable agreement in the troposphere, but did not compare to BHN, and did not compare to observations in the UTLS. Yu et al. (2010) compared nucleation rates and number concentration from IMN and two different BHN schemes in the troposphere to aircraft observations, but did not study the aerosol evolution (size, mass, effective radius) and did not study stratospheric properties. Kazil et al. (2010) found that simulations agree best with observations in the lower and mid-troposphere when IMN and BHN are included across the entire model domain and organic cluster formation is in- cluded but limited to the continental boundary layer, but did not compare to observations in the stratosphere. We present the first simulations using a sectional aerosol microphysical model that includes two different binary homogeneous nucleation schemes and an ion-induced nucleation scheme. We compare our simulations with UTLS observations of size distribution (Lee et al., 2003; Deshler et al., 2003), number concentration (Borrmann et al., 2010; Brock et al., 1995; Heintzenberg et al., 2003), and Stratospheric Aerosol and Gas Experiment (SAGE) II aerosol extinctions and effective radii (Chu et al., 1989).

\section{Model description}

We have constructed a three-dimensional general circulation model with sulfur chemistry and sectional aerosol microphysics. We use the Whole Atmosphere Community Climate Model (WACCM) (Garcia et al., 2007) coupled with the Community Aerosol and Radiation Model for Atmospheres (CARMA) (Toon et al., 1988). Figure 1 illustrates the processes treated in the coupled model. Model coupling is done by implementing a single column version of CARMA as a WACCM physics package. Results of this coupling for meteoric dust (Bardeen et al., 2008), noctilucent clouds (Bardeen et al., 2010) and black carbon (Mills et al., 2008; Ross et al., 2010) have been published previously. Other versions of the code have been used to simulate sea salt and dust (Fan and Toon, 2010; Su and Toon, 2011). The WACCM state is passed to CARMA one column at a time. CARMA calculates changes to the constituents, and the tendencies are sent back to WACCM where they are used to adjust the model's state. Each CARMA aerosol size bin 
Table 1. Sulfur reactions included in WACCM/CARMA. Reactions R1 through R12 obtained from NASA Jet Propulsion Laboratory Chemical Kinetics 15 th evaluation (Sander et al., 2006) with original citations also noted. Sander et al. combined numerous sources to determine rates R1, R7, R8, and R13.

\begin{tabular}{|c|c|c|c|}
\hline \multicolumn{4}{|c|}{ Binary Reactions } \\
\hline & Reaction & Rate $\left(\mathrm{cm}^{3} \mathrm{~s}^{-1}\right)$ & Source \\
\hline R1 & $\mathrm{OCS}+\mathrm{O} \rightarrow \mathrm{SO}+\mathrm{CO}$ & $2.1 \times 10^{-11} \exp (-2200 / \mathrm{T})$ & Sander et al. (2006) \\
\hline $\mathrm{R} 2$ & $\mathrm{OCS}+\mathrm{OH} \rightarrow \mathrm{SO}_{2}+\{\mathrm{C}\}+\mathrm{H}$ & $1.1 \times 10^{-13} \exp (-1200 / \mathrm{T})$ & Cheng and Lee (1986) \\
\hline $\mathrm{R} 3$ & $\mathrm{~S}+\mathrm{OH} \rightarrow \mathrm{SO}+\mathrm{H}$ & $6.6 \times 10^{-11}$ & Jourdain et al. (1978) \\
\hline $\mathrm{R} 4$ & $\mathrm{~S}+\mathrm{O}_{2} \rightarrow \mathrm{SO}+\mathrm{O}$ & $2.3 \times 10^{-12}$ & Davis et al. (1972) \\
\hline R5 & $\mathrm{S}+\mathrm{O}_{3} \rightarrow \mathrm{SO}+\mathrm{O}_{2}$ & $1.2 \times 10^{-11}$ & Clyne and Townsend (1975) \\
\hline R6 & $\mathrm{SO}+\mathrm{OH} \rightarrow \mathrm{SO}_{2}+\mathrm{H}$ & $2.70 \times 10^{-11} \exp (335 / \mathrm{T})$ & Blitz et al. (2000) \\
\hline R7 & $\mathrm{SO}+\mathrm{O}_{2} \rightarrow \mathrm{SO}_{2}+\mathrm{O}$ & $1.25 \times 10^{-13} \exp (-2190 / \mathrm{T})$ & Sander et al. (2006) \\
\hline $\mathrm{R} 8$ & $\mathrm{SO}+\mathrm{O}_{3} \rightarrow \mathrm{SO}_{2}+\mathrm{O}_{2}$ & $3.4 \times 10^{-12} \exp (-1100 / \mathrm{T})$ & Sander et al. (2006) \\
\hline R9 & $\mathrm{SO}+\mathrm{NO}_{2} \rightarrow \mathrm{SO}_{2}+\mathrm{NO}$ & $1.4 \times 10^{-11}$ & Brunning and Stief (1986a) \\
\hline $\mathrm{R} 10$ & $\mathrm{SO}+\mathrm{CLO} \rightarrow \mathrm{SO}_{2}+\mathrm{CL}$ & $2.8 \times 10^{-11}$ & Brunning and Stief (1986a) \\
\hline R11 & $\mathrm{SO}+\mathrm{BRO} \rightarrow \mathrm{SO}_{2}+\mathrm{BR}$ & $5.7 \times 10^{-11}$ & Brunning and Stief (1986b) \\
\hline $\mathrm{R} 12$ & $\mathrm{SO}+\mathrm{OCLO} \rightarrow \mathrm{SO}_{2}+\mathrm{CLO}$ & $1.9 \times 10^{-12}$ & Clyne and MacRobert (1981) \\
\hline R13 & $\mathrm{HSO}_{3}+\mathrm{O}_{2} \rightarrow \mathrm{SO}_{3}+\mathrm{HO}_{2}$ & $1.3 \times 10^{-12} \exp (-330 / \mathrm{T})$ & Sander et al. (2006) \\
\hline R14 & $\mathrm{SO}_{3}+\mathrm{H}_{2} \mathrm{O} \rightarrow \mathrm{H}_{2} \mathrm{SO}_{4}$ & $2.26 \times 10^{-23} \times \mathrm{T} \times \exp (6544 / \mathrm{T})$ & Lovejoy (1996) \\
\hline \multicolumn{4}{|c|}{ Ternary Reactions } \\
\hline & Reaction & Rate & Source \\
\hline $\mathrm{T} 1$ & $\mathrm{SO}_{2}+\mathrm{OH}+\mathrm{M} \rightarrow \mathrm{HSO}_{3}+\mathrm{M}$ & $\begin{array}{l}\text { k_o }=3.0 \times 10^{-31}(\mathrm{~T} / 300)^{4.3} \\
\text { k_infinity: } 1.6 \times 10^{-12}\end{array}$ & Blitz et al. (2003) \\
\hline \multicolumn{4}{|c|}{ Photolytic Reactions } \\
\hline & Reaction & & Source \\
\hline $\mathrm{J} 1$ & $\mathrm{H}_{2} \mathrm{SO}_{4}+\mathrm{h} v \rightarrow \mathrm{SO}_{3}+\mathrm{H}_{2} \mathrm{O}$ & & Vaida et al. (2003) \\
\hline $\mathrm{J} 2$ & $\mathrm{SO}_{2}+\mathrm{h} v \rightarrow \mathrm{SO}+\mathrm{O}$ & & Okabe (1978); Yung and DeMore (1982) \\
\hline $\mathrm{J} 3$ & $\mathrm{SO}_{3}+\mathrm{h} v \rightarrow \mathrm{SO}_{2}+\mathrm{O}$ & & Burkholder and McKeen (1997) \\
\hline $\mathrm{J} 4$ & $\mathrm{OCS}+\mathrm{h} v \rightarrow \mathrm{S}+\mathrm{CO}$ & & Molina et al. (1981) \\
\hline J5 & $\mathrm{SO}+\mathrm{h} v \rightarrow \mathrm{S}+\mathrm{O}$ & & Yung and Demore (1982) \\
\hline
\end{tabular}

is added as a unique WACCM constituent (Bardeen et al., 2008). Although CARMA is capable of interacting radiatively and chemically with WACCM, for these studies the interactions were mainly disabled. This version of WACCM utilizes SAGE II sulfate surface area densities for radiative transfer and ozone heterogeneous chemistry calculations.

\subsection{WACCM with sulfur chemistry}

We use WACCM3 version 3.1.9 tag 9 with 30-min time steps at $4^{\circ}$ latitude by $5^{\circ}$ longitude horizontal resolution with 66 vertical levels based on hybrid-sigma coordinates, providing 15 vertical levels in the UTLS between 50 and $500 \mathrm{hPa}$. We use the WACCM mass-conserving finite volume dynamical core based on a flux-form semi-Langrangian transport scheme (Lin and Rood, 1996, 1997). The vertical diffusion algorithm in WACCM handles eddy and molecular diffusion for gases. A 63-species chemistry module is implemented.
We utilize WACCM's standard 56-species chemical package which includes $\mathrm{O}_{\mathrm{x}}, \mathrm{NO}_{\mathrm{x}}, \mathrm{HO}_{\mathrm{x}}, \mathrm{ClO}_{\mathrm{x}}$, and $\mathrm{BrO}_{\mathrm{x}}$ chemical families along with $\mathrm{CH}_{4}$ and its products and 7 ions (Kinnison et al., 2007), and add 7 sulfur-bearing gases: S, SO, $\mathrm{SO}_{2}, \mathrm{SO}_{3}, \mathrm{HOSO}_{2}, \mathrm{H}_{2} \mathrm{SO}_{4}$, and OCS. Their reaction rates and photo-dissociation rates are given in Table 1 .

The model includes emissions of carbonyl sulfide (OCS) and sulfur dioxide $\left(\mathrm{SO}_{2}\right)$, two primary sulfur emissions of importance to the UTLS region. OCS is specified with a constant surface concentration of 510 pptv. $\mathrm{SO}_{2}$ is specified from a two-dimensional monthly mean surface emissions dataset (Lamarque et al., 2010; Smith et al., 2011). The model does not include emissions of dimethylsulfide or volcanic $\mathrm{SO}_{2}$, which are large natural sources of sulfur to the UTLS, but minor contributions to total UTLS aerosol. We compare with data from a period with relatively little volcanic activity. Wet deposition for all constituents (including the aerosol 
bins from CARMA) is calculated using WACCM's existing techniques (Barth et al., 2000). All of the aerosol bins are assumed to have a constant 0.3 solubility parameter. WACCM treats dry deposition of gases (Barth et al., 2000), while dry deposition of aerosols is not treated in this model.

\subsection{CARMA}

We use CARMA 2.3 configured for one-dimensional columns using the same vertical grid as WACCM. Split-time stepping is enabled for nucleation and growth routines when sulfuric acid is supersaturated. Nucleation and growth are treated simultaneously in the model. If sulfuric acid gas concentrations become unstable (negative), the CARMA time step is retried with double the number of substeps. On rare occurrences the model reached over 1000 substeps, but typically the model ran with only 1 or 2 substeps. We have found that increasing the number of timesteps past the point at which negative gas amounts were found did not significantly change results. Additionally, we limited nucleation to $40 \%$ of the sulfuric acid available. We specify 38 sulfuric acid mass bins ranging from $0.2 \mathrm{~nm}$ to 1 micron radius, with mass doubling between bins. The particles are assumed to have spherical shape. Sulfate surface tension is calculated using the constants from Sabinina and Terpugow (1935). Since the bins only carry sulfate, the equivalent sulfate aerosol size (including sulfuric acid and water) is determined by the technique of Tabazadeh et al. (1997), which calculates weight percent sulfuric acid as a function of temperature and water activity. Weight percent sulfuric acid is assumed to be independent of particle size. We did not include any other types of aerosols. Although other aerosols, such as organics, are known to compose a significant fraction of the sulfate aerosol mass in the UTLS (Froyd et al., 2009; Murphy et al., 2007), sulfates are believed to be the primary source of new particles in this region, and the primary aerosol in the lower and middle stratosphere (Murphy et al., 2007).

Fall velocities are calculated by assuming a StokesCunningham equation with Knudsen number corrections from Fuchs (1964), using the equivalent aerosol size (sulfuric acid plus water). Since WACCM handles advection by winds as well as eddy diffusion, no additional eddy diffusion of aerosol particles is added by CARMA. However, CARMA treats Brownian diffusion of aerosols, which becomes important above $100 \mathrm{~km}$ as the heterosphere is approached, and which is not well treated by algorithms in WACCM. CARMA calculates the effect of coagulation of particles of equivalent aerosol size using the numerical approach described in Toon et al. (1988). Coagulation coefficients are calculated to include Brownian, convective and gravitational effects. A sticking coefficient of 1 is used, which assumes that all particles stick together upon colliding. A correction for the impact of inter-particle Van der Waals forces on coagulation is included (Chan and Mozurkewich, 2001). Sulfate aerosol growth and evaporation is calculated via sulfuric acid equilibrium vapor pressure over binary solution using the method of Ayers et al. (1980) with a temperature correction by Kulmala (1990) and thermodynamic constants from Giauque (1959). Numerical calculations for fall velocity and growth/evaporation are solved by CARMA using the piecewise parabolic method of Colella and Woodward (1984).

\subsection{Description of nucleation schemes}

Three nucleation schemes are implemented in CARMA: two binary homogeneous nucleation (BHN) schemes and one ion-mediated nucleation (IMN) scheme.

\subsubsection{Zhao BHN scheme}

The "Zhao BHN" scheme predicts the binary homogeneous nucleation rate of sulfuric acid and water using classical nucleation theory (e.g. Flood, 1934; Reiss, 1950; Hamill et al., 1977) with modifications for calculating the saddle point in Gibbs free energy by Zhao and Turco (1995). Instead of searching for the Gibbs free energy saddle point in twodimensional space, the coordinate system is transformed to a function of cluster volume and sulfuric acid weight fraction of a solution droplet. This provides for a unique solution in a 1-dimensional parameter space. Water equilibrium vapor pressure over a binary solution is calculated using the technique of Lin and Tabazadeh (2001). Sulfuric acid equilibrium vapor pressure over binary solution is calculated in the same manner as aerosol growth/evaporation: using the method of Ayers et al. (1980) with a temperature correction by Kulmala (1990) and thermodynamic constants from Giauque (1959). Many similar schemes for BHN have been published (Kulmala, 1990) with varying choices for thermodynamic parameters. Since these schemes are analytic they generally are well behaved over the entire range of parameter space covered in WACCM, although their predicted nucleation rates are known to vary by an order of magnitude or more.

\subsubsection{Yu BHN scheme}

The "Yu BHN" scheme predicts the binary homogeneous nucleation rate of sulfuric acid and water by assuming the "quasi-unary" nucleation of sulfuric acid in equilibrium with water vapor (Yu, 2008), also known as kinetic nucleation theory. Since the growth of clusters is largely determined by the availability of sulfuric acid, the binary nucleation can be reduced to unary nucleation of sulfuric acid except that the clusters containing different numbers of sulfuric acid molecules also contain a semi-fixed number of water molecules at a given temperature and relative humidity. The kinetically self-consistent "Yu BHN" model is constrained by the measured bonding energetics of $\mathrm{H}_{2} \mathrm{SO}_{4}$ monomers with hydrated sulfuric acid dimers and trimers (Hanson and Lovejoy, 2006; Kazil et al., 2007) and gives BHN nucleation 
rates in good agreement with available experimental data. While the laboratory data used to constrain the "Yu BHN" model substantially reduces the model uncertainty, they were measured under tropospheric conditions and can't be extrapolated to dry stratospheric conditions. As a result, the application of the present "Yu BHN" scheme should be limited to the troposphere. The "Yu BHN" scheme is available as a set of two lookup tables, a low temperature Table for temperatures between 180 and $250 \mathrm{~K}$, and a high temperature Table for temperatures between 250 and $300 \mathrm{~K}$. The low temperature Table is five-dimensional, with inputs for sulfuric acid concentration, relative humidity, temperature, preexisting aerosol surface area, and ion-pairs. (Ion pairs are set to zero for BHN simulations). The high temperature Table is three-dimensional, with inputs for sulfuric acid concentration, relative humidity, and temperature. If input values are outside of the limits of the table, the values are adjusted to the boundary values. As mentioned earlier, this scheme was developed for the troposphere and the tables do not cover the full range of relative humidity, surface area and temperature found above the middle stratosphere. It was discovered that the tables predict unrealistic nucleation rates in the middle and upper stratosphere, due to relative humidity being adjusted from calculated values as low as $10^{-8}$ to the Table minimum values $(0.1 \%$ for the low temperature Table and $1 \%$ for the high temperature table). The problem of extending the range of the tables was largely resolved by setting the nucleation rate to zero if $\mathrm{RH}$ was less than the Table minimums. However, there may remain some unrealistic nucleation rates in the middle stratosphere and above due to the boundary conditions of the lookup tables. The tables should be used with caution in these regions.

\subsubsection{Yu IMN scheme}

The "Yu IMN" scheme predicts ion-mediated nucleation rates of sulfuric acid and water. Ions of positive and negative charge stabilize the molecular cluster due to molecular attractions of opposite polarity. This scheme uses the same low temperature lookup Table as the Yu BMN scheme, while a different high temperature Table is used, as described in $\mathrm{Yu}$ (2010). For the Yu IMN scheme, a globally constant input value of 10 ion-pairs per $\mathrm{cm}^{3}$ is prescribed. Although the ionization rate varies spatially and temporally, it is relatively constant in the UTLS and is estimated to be between 5 and 20 ion-pairs per $\mathrm{cm}^{3}$ (Usoskin et al., 2009). This Table was developed for tropospheric conditions as well and thus has the same limitations as the Yu BHN scheme. Thus, nucleation was set to zero if relative humidity was below the Table minimum values $(0.1 \%$ for the low temperature Table or $0.3 \%$ for the high temperature table).

\section{Model evaluation}

We have found that for most particle properties all three nucleation schemes produce nearly identical results. Therefore, below we first compare simulations using one nucleation scheme (Zhao BHN) with observations. Later we highlight where the schemes differ. Initial values for atmospheric state, gas properties and aerosol properties are read in from a baseline run with a 5-year spinup time. A three-year simulation was conducted, with the third year analyzed. Analysis of sulfate mass and number concentration indicate that the model achieved steady state in less than one year when using the common spin-up file.

\subsection{Simulations of sulfur gas precursors}

Calculated OCS is uniformly mixed in the troposphere (Fig. 2a), due to its long photochemical lifetime there. In the stratosphere, its mixing ratio decreases with altitude due to photolytic conversion of OCS to $\mathrm{SO}_{2}$. Figure $2 \mathrm{~b}$ shows OCS correlated with $\mathrm{N}_{2} \mathrm{O}$, a long-lived tracer with wellunderstood chemistry, from our calculations as well as from balloon-borne observations (Geoff Toon, private communication). The close agreement in the slope of this correlation indicates that the model correctly treats photochemical losses of OCS.

Calculated surface $\mathrm{SO}_{2}$ concentrations vary by five orders of magnitude across the earth's surface (Fig. 3a), with highest concentrations in the industrial mid-latitudes, particularly in eastern Asia, eastern United States, and Europe. $\mathrm{SO}_{2}$ mixing ratio decreases with altitude in the troposphere (Fig. 3b), with the highest concentrations near $30^{\circ} \mathrm{N}$, correlating with the peak latitude of surface emissions. $\mathrm{SO}_{2}$ mixing ratios decrease rapidly just above the tropopause due to slow vertical transport relative to chemical loss mainly by reaction with $\mathrm{OH}$. A peak occurs in the tropics above $25 \mathrm{~km}$ where OCS is converted into $\mathrm{SO}_{2}$, and $\mathrm{SO}_{2}$ increases again in the upper stratospheric due to photolytic conversion of $\mathrm{H}_{2} \mathrm{SO}_{4}$ back to $\mathrm{SO}_{2}$ (Mills et al., 2005).

Figure 4a shows latitudinal variation in $\mathrm{SO}_{2}$ mixing ratios in the Pacific upper troposphere between 8 and $12 \mathrm{~km}$ from model calculations and PEM-TA, PEM-TB, and ACE2 aircraft observations (Thornton et al., 1999). Our calculations are slightly lower than the observations, but generally within or close to the observed variability. Figure $4 \mathrm{~b}$ shows vertical profiles of $\mathrm{SO}_{2}$ mixing ratios compared to 6 ACE-2 aircraft observations (Curtius et al., 2001). Our calculations are generally within the measurement variability expressed by the error bars although the model overpredicts the $\mathrm{SO}_{2}$ observations in the upper troposphere above $300 \mathrm{hPa}$. The observations are limited to a narrow latitude range of $28-32^{\circ} \mathrm{N}$. As shown by the calculations from various latitudes, $\mathrm{SO}_{2}$ concentrations are a strong function of latitude (and longitude) in this range. Compared to PEMTB aircraft observations in the tropics (Wang et al., 2001) 

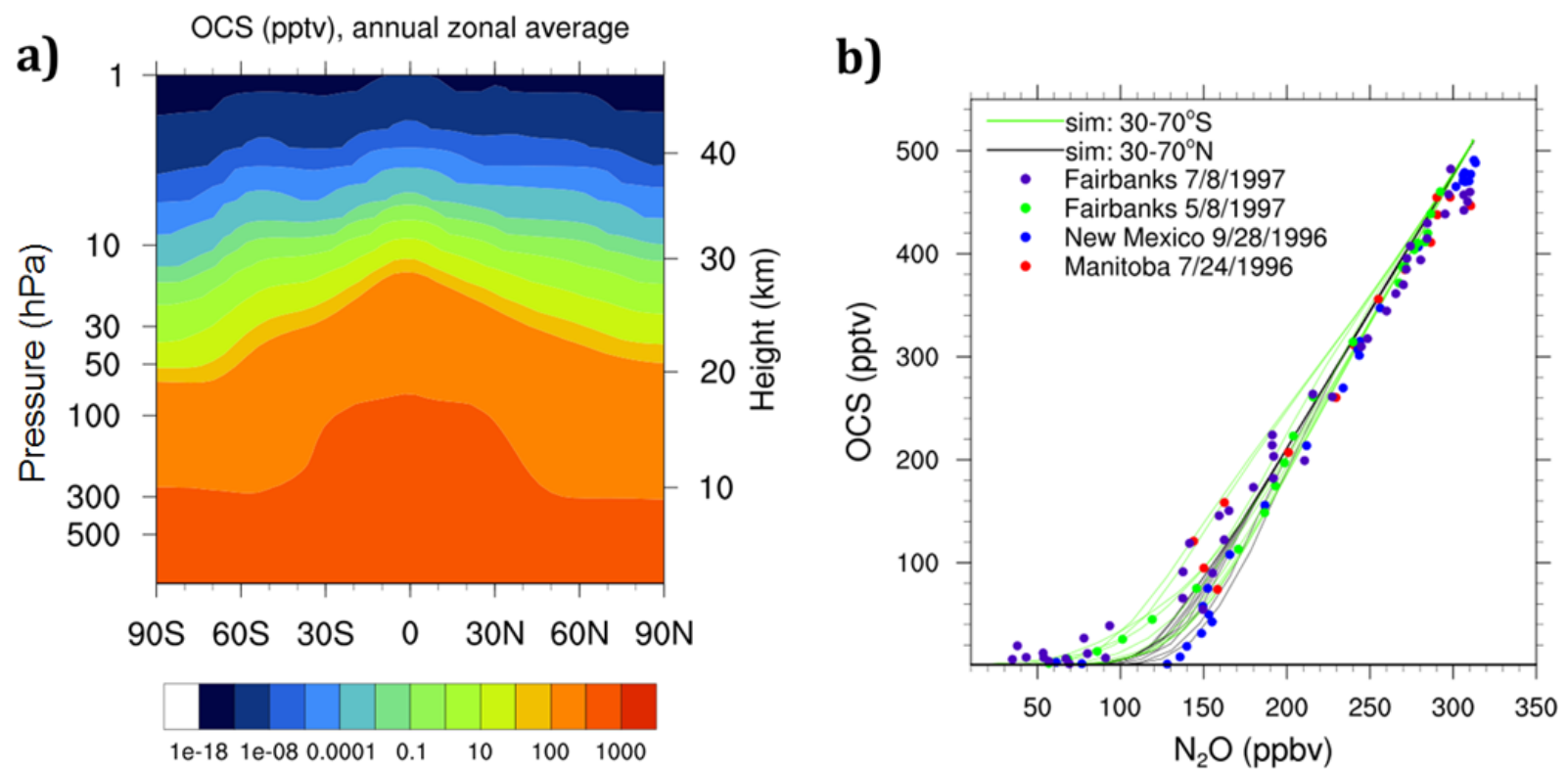

Fig. 2. (a) Calculated OCS mixing ratio; annual and zonal average as a function of atmospheric pressure and latitude. (b) Calculated OCS versus $\mathrm{N}_{2} \mathrm{O}$, compared to balloon observations by Geoff Toon (private communication). Observations are from ascent and descent profiles at dates and locations noted. Simulation lines are an average of JJA at the latitude ranges noted. Each simulation line represents model output at a specific latitude at $4^{\circ}$ increments between $30^{\circ}$ and $70^{\circ}$ at all longitudes.
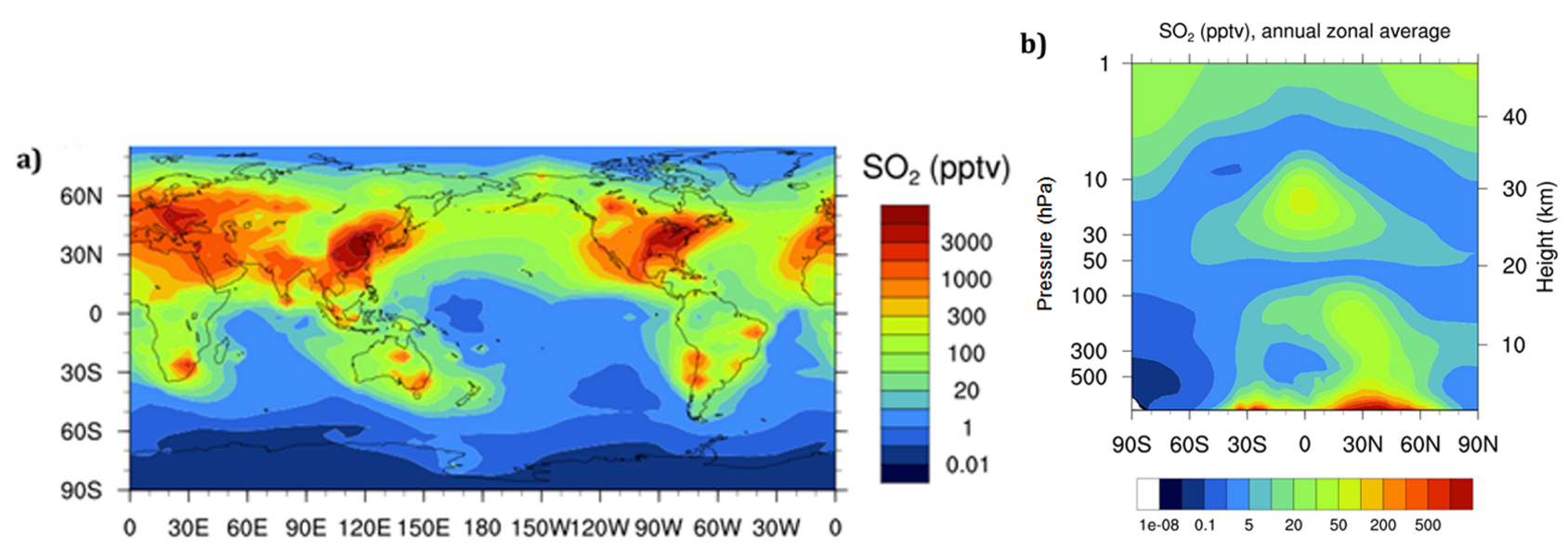

Fig. 3. (a) Calculated surface $\mathrm{SO}_{2}$ mixing ratio; annual average as a function of latitude and longitude. (b) Calculated $\mathrm{SO}_{2}$ mixing ratio; annual and zonal average as a function of atmospheric pressure and latitude.

(Fig. 4c), the model overpredicts near the surface and underpredicts above $700 \mathrm{hPa}$. It is possible that the lack of dimethylsulfide emissions in the model contributes to lower $\mathrm{SO}_{2}$ concentrations in the mid-troposphere at non-industrial latitudes. Overall, considering the limited number of observations and the high variability of available observations, we conclude that the model $\mathrm{SO}_{2}$ emissions and chemistry are generally well-behaved. It would be extremely valuable for UTLS studies to obtain $\mathrm{SO}_{2}$ observations above $200 \mathrm{hPa}$.

Sources of $\mathrm{H}_{2} \mathrm{SO}_{4}$ vapor in the model are $\mathrm{SO}_{2}$ and OCS oxidation and aerosol evaporation, while sinks include nu- cleation, condensation, and photolysis at high altitudes. As shown in Fig. 5a, calculated $\mathrm{H}_{2} \mathrm{SO}_{4}$ vapor mixing ratios increase from 25 to $35 \mathrm{~km}$ due to sulfate aerosol evaporation. It is so warm and dry above $35 \mathrm{~km}$ that the sulfuric acid vapor pressure exceeds the total (gas + particle) mixing ratio of sulfuric acid; hence the particles completely evaporate. $\mathrm{H}_{2} \mathrm{SO}_{4}$ also has a local maximum in the Northern Hemisphere subtropical upper troposphere due to availability of $\mathrm{SO}_{2}$ and $\mathrm{OH}$ for chemical conversion. As Fig. 5b shows, calculated $\mathrm{H}_{2} \mathrm{SO}_{4}$ mixing ratios are generally within the standard deviation of PEM-TA aircraft observations (Lucas and Prinn, 

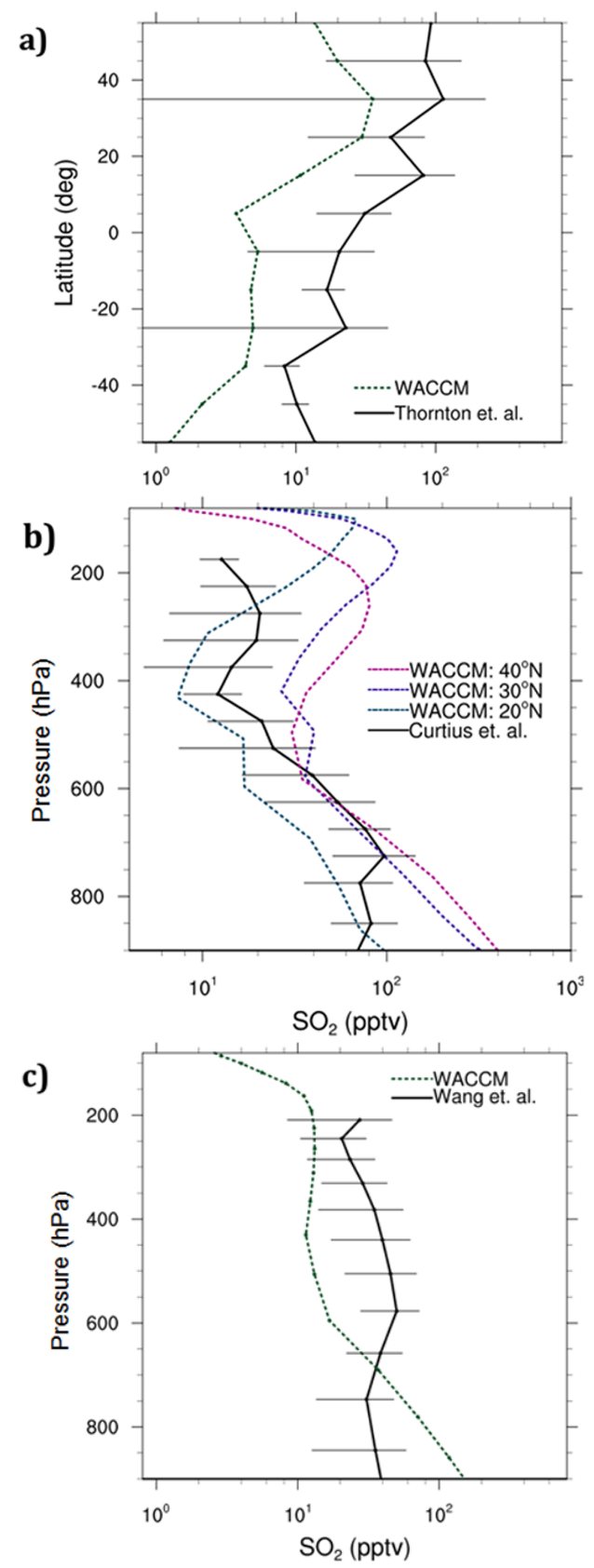

Fig. 4. (a) Calculated $\mathrm{SO}_{2}$ concentration between $8-12 \mathrm{~km}$ at varying latitudes compared to an average of Pacific Exploratory Mission (PEM)-West A, PEM-West B, and Atmospheric Chemistry Experiment (ACE)-2 aircraft observations over the $\mathrm{Pa}$ cific Ocean between $110^{\circ} \mathrm{E}$ and $80^{\circ} \mathrm{W}$, binned into 10-degree segments with error bars representing plus/minus one standard deviation (Thornton et al., 1999). Model calculations are an annual average in the same longitude and altitude region. (b) Vertical profiles of calculated $\mathrm{SO}_{2}$ mixing ratio at different latitudes compared to ACE-2 aircraft observations (Curtius et al., 2001). Observations are an average and standard deviation of 6 flights in July 1997 from $28^{\circ} \mathrm{N}$ to $32^{\circ} \mathrm{N}$. Simulation lines are an average of the month of July at each of the latitudes noted. (c) Vertical profile of calculated $\mathrm{SO}_{2}$ mixing ratio between $30^{\circ} \mathrm{N}$ and $30^{\circ} \mathrm{S}$ compared to PEM-TB aircraft observations (Wang et al., 2001). Observations are an average and standard deviation of DC-8 flights between $38^{\circ} \mathrm{N}$ and $36^{\circ} \mathrm{S}$ in March and April 1999. Simulation is an average of March and April from $38^{\circ} \mathrm{N}$ to $36^{\circ} \mathrm{S}$.
2003). $\mathrm{H}_{2} \mathrm{SO}_{4}$ averages about $0.1 \mathrm{pptv}$ throughout most of the UTLS. As Fig. $5 \mathrm{c}$ shows, calculated $\mathrm{H}_{2} \mathrm{SO}_{4}$ concentrations in the stratosphere at $43^{\circ} \mathrm{N}$ closely match balloonborne observations (Arnold et al., 1981; Reiner and Arnold, 1997; Schlager and Arnold, 1987; Viggiano and Arnold, 1981), with a peak near $35 \mathrm{~km}$.

\subsection{Sulfate aerosol properties}

Calculated sulfate mass mixing ratios versus $\mathrm{N}_{2} \mathrm{O}$ are compared to a compilation of NASA aircraft observations (Wilson et al., 2008) in Fig. 6. Calculated sulfate mass mixing ratio generally is within the variability in the mid-latitude UTLS ( 220 to 300 ppbv $\mathrm{N}_{2} \mathrm{O}$ ). Calculated sulfate mass mixing ratio is about $50 \%$ too high at low $\mathrm{N}_{2} \mathrm{O}$ values (polar mid-stratosphere). It is possible that simulated sedimentation rates are to slow in the midlatitude stratosphere. Recent calculations with our WACCM/CARMA model including both sulfates and meteoric dust improves this correlation. However, as we will discuss below our model underpredicts aerosol volume (also measured by Wilson et al., 2008) versus $\mathrm{CO}$. It is possible that these conflicting differences in aerosol volume and sulfate mass versus tracer abundance are related to transport or tracer chemistry issues within WACCM. It is also possible there are errors in the observations, or errors with comparing aircraft flights on particular days with averaged model data.

Model calculations are compared to SAGE II extinction measurements at two wavelengths in Fig. 7. Here, the calculation is within about $50 \%$ of the observations at both wavelengths for all three latitude regions from the tropopause through the mid-stratosphere. Below the tropopause, SAGE II has higher extinction than the calculations, with high variability. It is likely clouds are interfering with measurements below the tropopause, as has been noted in prior analyses of SAGE II extinction measurements (Wang et al., 1995, 1996). In the upper stratosphere, WACCM extinctions decline sharply with higher altitude, while SAGE II extinctions level off at about $10^{-6} \mathrm{~km}^{-1}$ at $1024 \mathrm{~nm}$ near $35 \mathrm{~km}$. Hervig et al. (2009) have observed from AIM solar occultation measurements that micrometeorites, sedimenting down from the mesopause, have an extinction near $10^{-6}$ at $1037 \mathrm{~nm}$ near $35 \mathrm{~km}$. Recent calculations with our WACCM/CARMA model including both sulfates and meteoric dust improves this correlation between the model and SAGE II data above $35 \mathrm{~km}$, reinforcing this suggestion. Hunten et al. (1980) originally suggested the presence of these particles, and they have long been sought in rocket measurements with little quantitative success. It is interesting that SAGE II has seen them throughout its observational record, but their presence was not recognized.

While WACCM extinction is within $50 \%$ of SAGE II in the mid-latitudes, WACCM is higher than SAGE II at $1024 \mathrm{~nm}$ in the tropics, suggesting that the WACCM particles are slightly too large in the tropics. Indeed, calculated 

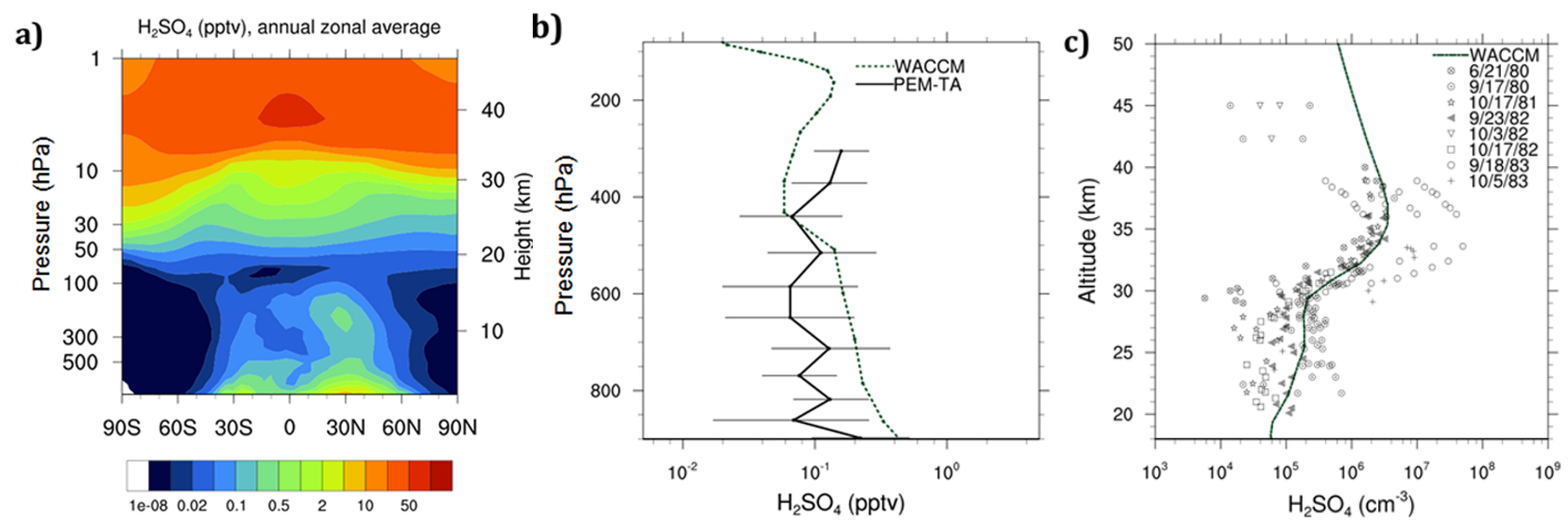

Fig. 5. (a) Calculated $\mathrm{H}_{2} \mathrm{SO}_{4}$ mixing ratio; annual and zonal average as a function of atmospheric pressure and latitude. (b) Vertical profile of calculated $\mathrm{H}_{2} \mathrm{SO}_{4}$ mixing ratio compared to PEM-TA (Bates et al., 1998; Hoell et al., 1999) aircraft observations binned into averages plus/minus standard deviation at different altitudes (Lucas and Prinn, 2003) from flights in August and September 1996 between $24^{\circ} \mathrm{N}$ and $24^{\circ} \mathrm{S}$. Simulation lines are an average of July and August between $24^{\circ} \mathrm{N}$ and $24^{\circ} \mathrm{S}$. (c) Vertical profile of calculated $\mathrm{H}_{2} \mathrm{SO}_{4}$ number concentration at $43 \mathrm{~N}$ compared to various balloon-borne observations at the same latitude (Arnold et al., 1981; Reiner and Arnold, 1997; Schlager and Arnold, 1987; Viggiano and Arnold, 1981). Simulation is an average of the months of September and October while the observations were taken at the dates listed.
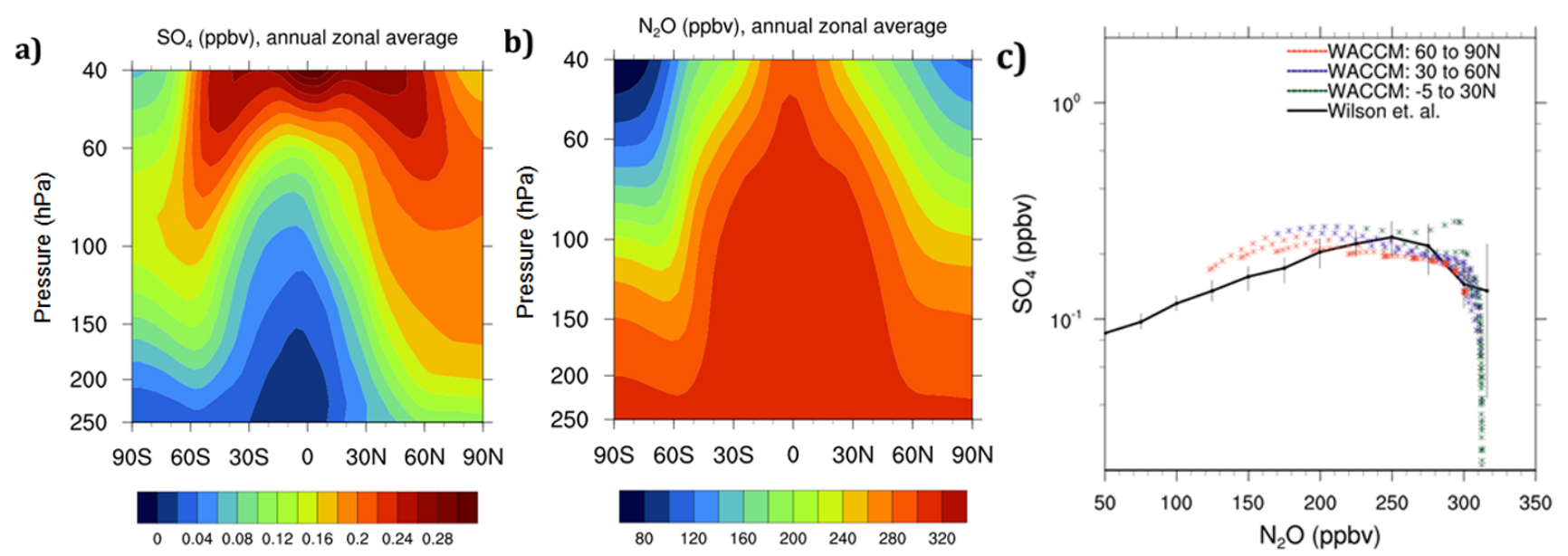

Fig. 6. (a) Calculated $\mathrm{SO}_{4}$ mixing ratio; annual and zonal average as a function of atmospheric pressure and latitude. (b) Calculated $\mathrm{N}_{2} \mathrm{O}$ mixing ratio; annual and zonal average as a function of atmospheric pressure and latitude. (c) Calculated $\mathrm{SO}_{4}$ mixing ratio versus $\mathrm{N}_{2} \mathrm{O}$ compared to a compilation of aircraft observations (Wilson et al., 2008). Observations are an average of volcanically quiescent aircraft observations between 1999 and 2004 taken from NASA ER-2, WB-57 and DC-8. The aircraft measurements spanned $5^{\circ} \mathrm{S}$ to $90^{\circ} \mathrm{N}$ latitude and approximately 40 to $250 \mathrm{hPa}$. Simulation points are annual zonal average of each grid cell between 40 and $250 \mathrm{hPa}$ at the latitudes specified.

effective particle radius (Fig. 8) is about $25 \%$ higher than SAGE II in the UTLS. Model calculations of size distributions in the UTLS at $41^{\circ} \mathrm{N}$ are compared to balloon-borne observations (Deshler et al., 2003) in Fig. 9. Vertical profiles of calculated particle concentration are within $50 \%$ of observations at the smallest size ( $>0.01$ microns), while at larger sizes the model underpredicts number concentration below the tropopause and overpredicts number concentration in the mid-stratosphere.

Vertical profiles of calculated sulfate number concentration in the nm size range are compared to aircraft observations (Borrmann et al., 2010; Brock et al., 1995) in Fig. 10. Here, two Zhao BHN calculations are compared: a run with Brownian coagulation and no inter-particle forces (noVW), 

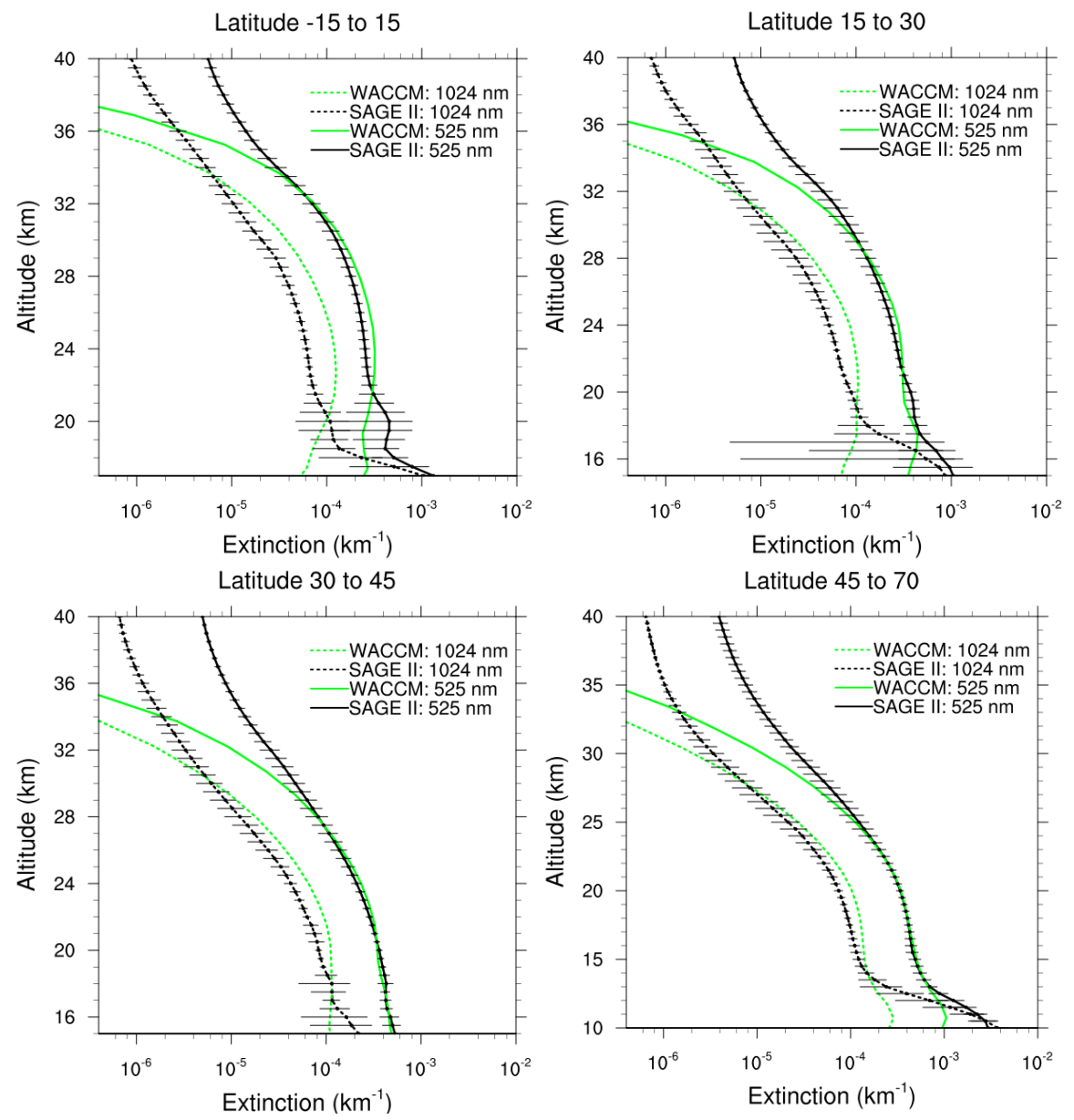

Fig. 7. Calculated sulfate extinction compared to Stratospheric Aerosol and Gas Experiment (SAGE) II satellite retrievals (Chu et al., 1989) at two wavelengths $(525 \mathrm{~nm}$ and $1024 \mathrm{~nm})$ and the latitude regions specified. SAGE data are averaged from years 2000-2005. Simulations are 1-year average. Simulated extinction coefficients are calculated as a function of weight percent and wavelength using the refractive indices of Palmer and Williams (1975).

and our base case in which the Brownian coagulation kernels are adjusted to include the effect of a Van der Waals forces between the particles. Van der Waals forces have been observed to be important for sulfuric acid aerosols in several laboratory studies (Schmid-Ott and Burtscher, 1982; Alam, 1987; Huang et al., 1990) and we include a size-dependent expression for the Hamaker constant based on laboratory measurements (Chan and Mozurkewich, 2001). In both the tropics (Fig. 10a) and extratropics (Fig. 10b), calculated and observed particle mixing ratios increase in the troposphere, peak near the tropopause where the highest nucleation rates are observed, and decrease in the stratosphere, as expected. Including the effect of Van der Waals forces on coagulation results in calculations that are within the error bars of the observations. Prior to including the effect of Van der Waals forces on coagulation, the model had always overpredicted particle mixing ratio in the mid-stratosphere despite modifications to nucleation schemes, sulfur emissions, fall velocity schemes, and growth equations. The impact of including Van der Waals forces highlights how important coagulation rates are to stratospheric aerosol properties.

Calculated aerosol number, area, and volume versus carbon monoxide (CO) are compared to an average of 13 flights in the tropical UTLS between 2004 and 2006 in Fig. 11. Again, the Zhao BHN calculations with and without the Van der Waals coagulation correction are compared. Calculated number concentrations (Fig. 11b) for both simulations are within the error bars at lower $\mathrm{CO}$, but increase to up to an order of magnitude too high above $55 \mathrm{ppbv} \mathrm{CO}$. In the model, this $\mathrm{CO}$ region is present near $200 \mathrm{hPa}$ and $20^{\circ} \mathrm{N}$, where the model predicts peak nucleation. It is possible that the model and data do not have corresponding geographical areas with the same $\mathrm{CO}$ values. Model output were too limited in the range of longitudes covered by aircraft observations, so all longitudes were included. The Zhao no VW scheme predicts higher aerosol number where peak nucleation is observed, 

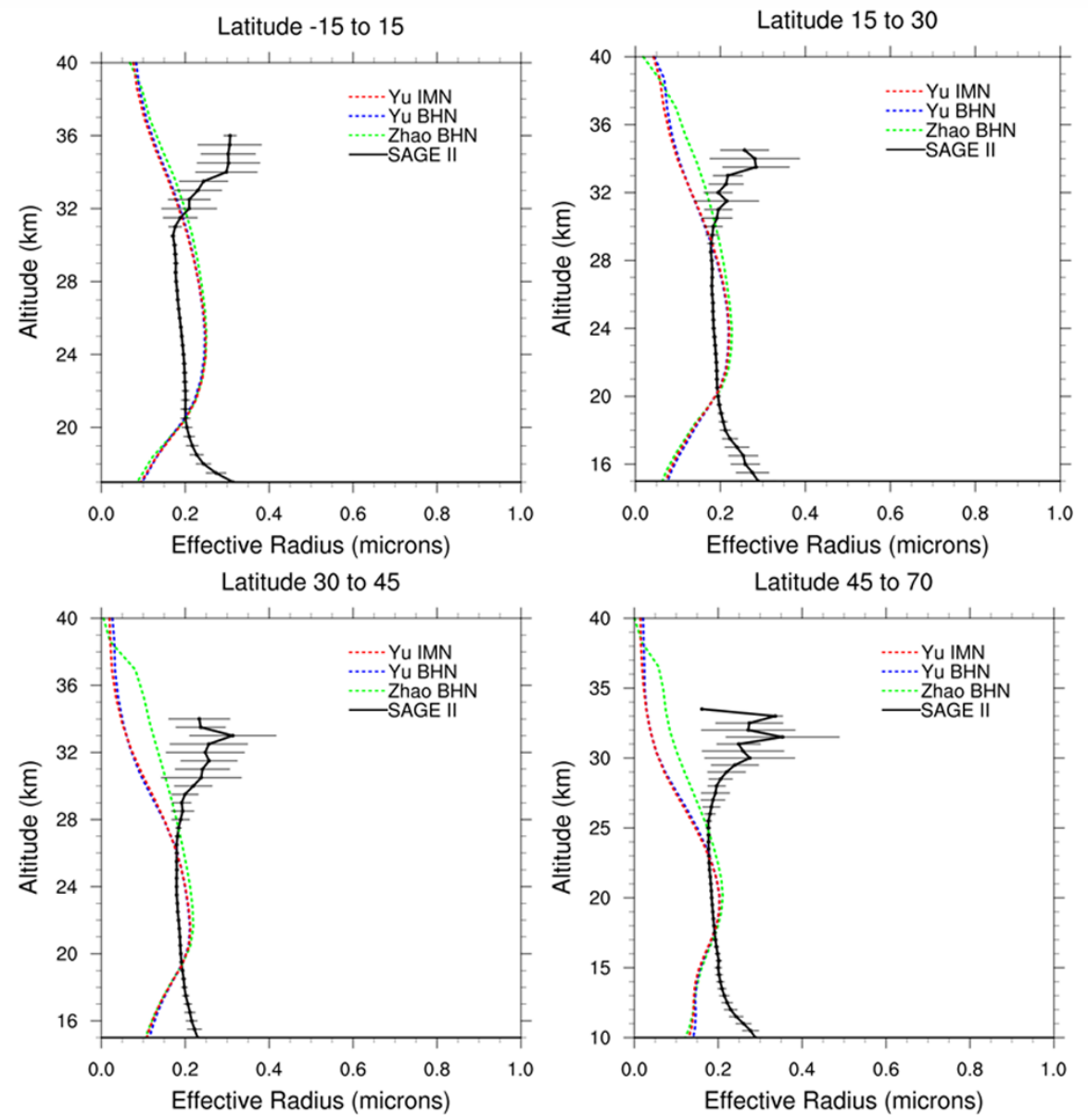

Fig. 8. Calculated sulfate effective radius compared to SAGE II satellite retrievals at the latitude regions specified. SAGE data are averaged from years 2000-2005. Simulations are 1-year average, using wet particle radii for calculations.
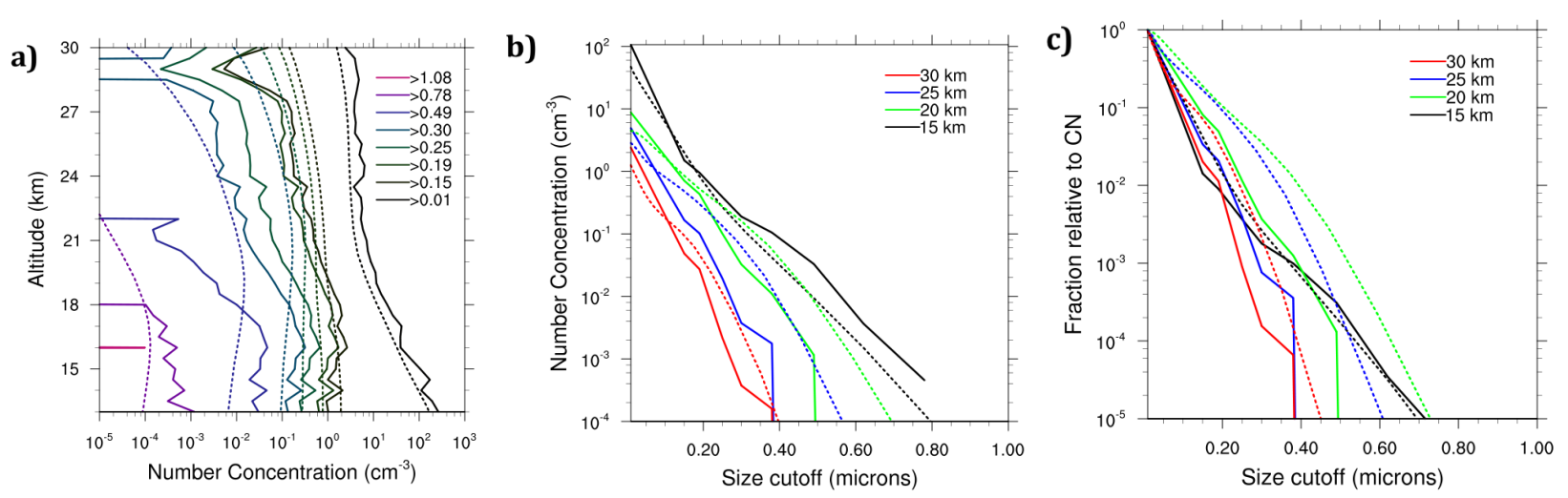

Fig. 9. Calculated size distributions for the Zhao BHN simulation (dotted lines) compared to balloon-borne observations above Wyoming (Deshler et al., 2003) (solid lines) at specified wet particle radii in microns. Observations are an average of years 2000-2010. Simulations are an annual average at $41^{\circ} \mathrm{N}$ and $104^{\circ} \mathrm{W}$. (a) Vertical profile of number concentration larger than specified minimum radii. Calculated number concentrations were calculated using the closest bin to the specified wet radius. (b) Number concentration larger than a specified wet radius cutoff at the altitudes specified. (c) Ratio of number concentrations larger than the specified wet radius to number concentrations of condensation nuclei ( $>0.01$ microns wet radius). 

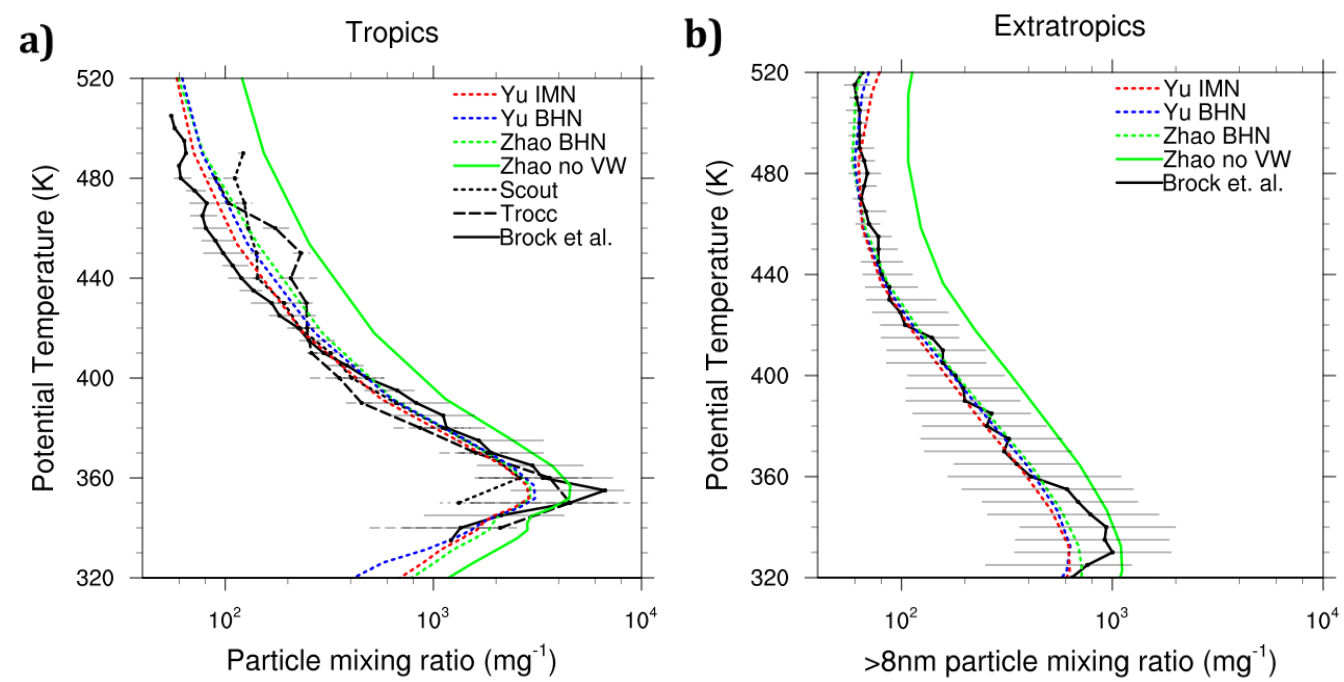

Fig. 10. (a) Vertical profile of calculated sulfate particle mixing ratios in the tropics $\left(30^{\circ} \mathrm{S}\right.$ to $\left.30^{\circ} \mathrm{N}\right)$ compared to aircraft observations (Borrmann et al., 2010). (b) Vertical profile of calculated sulfate particle mixing ratios in the extratropics (average of $30^{\circ} \mathrm{S}$ to $90^{\circ} \mathrm{S}$ and $30^{\circ} \mathrm{N}$ to $90^{\circ} \mathrm{N}$ ) compared to aircraft observations (Brock et al., 1995). Observations are medians plus/minus 25 th/75th percentiles. Brock et al. mixing ratios include particles greater than $8 \mathrm{~nm}$ diameter and are based on 5 worldwide aircraft campaigns between 1987 and 1994 , with data points attributed to the eruption of Mt. Pinatubo removed. Scout (SCOUT-O3; Stratospheric-Climate Links with Emphasis on the Upper Troposphere and Lower Stratosphere) and Trocc (TROCCINOX; Tropical Convection, Cirrus, and Nitrogen Oxides Experiment) mixing ratios include particles greater than $6 \mathrm{~nm}$ diameter and are from 2005 aircraft campaigns. It is assumed that no water is present on the particles. Calculated mixing ratios in both regions include $8.0 \mathrm{~nm}$ dry diameter and larger. The "Zhao no VW" simulation uses Brownian coagulation kernels based on collision theory, while the other three simulations include the effect of Van der Waals forces on the collision cross section using the calculations of Chan and Mozurkewich (2001).

but lower number outside this region. Calculated aerosol area (Fig. 11c) and volume (Fig. 11d) are about half the observations. It is odd that the model underestimates aerosol area and volume in the Northern Hemisphere between $3^{\circ} \mathrm{S}$ and $23^{\circ} \mathrm{N}$, yet overestimates aerosol mass in the Northern Hemisphere between 60 and $90^{\circ} \mathrm{N}$ (Fig. 6c). The comparisons are made with coordinates of $\mathrm{CO}$ and $\mathrm{N}_{2} \mathrm{O}$, respectively, rather than geographic location, so this discrepancy may be due to differences between modeled and observed geographic locations or errors in the observations. Additionally, the Zhao no VW predicts higher nucleation at higher $\mathrm{CO}$ but lower nucleation at lower CO, as shown in Fig. 11b. The Zhao no VW area plot (Fig. 11b) is higher than with the VW correction due to slower growth rates.

\section{Simulations with different nucleation schemes}

We analyze model output for three simulations, one for each nucleation scheme: Zhao BHN, Yu BHN, and Yu IMN. Simulations are each 3 years in length (with initialized values from a shared 5-year spin-up simulation). All three schemes were computationally similar in efficiency, requiring approximately $11 \mathrm{~h}$ to complete 3 -years of simulation time on 96 dual-core processors on the NASA Pleiades supercomputer. The microphysical model reduced computing speed by about a factor of 2. Unless otherwise indicated, comparisons are done using the average of the 3rd year of the simulations.

\subsection{Differences in nucleation rates}

Contour plots of calculated nucleation rates are provided in Fig. 12, while peak and average nucleation rates and critical radii sizes in the UTLS are provided in Table 2. All three schemes predict similar patterns of nucleation - the highest rates are predicted in the tropical upper troposphere, with lower nucleation rates predicted in other parts of the troposphere and polar stratosphere, but their magnitudes differ significantly. Near the surface, the Yu IMN scheme predicts several orders of magnitude higher nucleation rates than the $\mathrm{Yu}$ BHN, suggesting that ion nucleation from cosmic rays can have a large influence on new particle formation in this region, in agreement with many other studies (Yu and Turco, 2001; Lovejoy et al., 2004; Eisele et al., 2006; Kazil et al., 2010; Snow-Kropla et al., 2011). In the UTLS, where conditions are favorable for BHN, the Yu IMN scheme predicts only $25 \%$ higher nucleation rates than the Yu BHN scheme, consistent with some studies (e.g. Kazil et al., 2010) but different from others (e.g., Yu et al., 2010). Since BHN is favored under highly supersaturated $\mathrm{H}_{2} \mathrm{SO}_{4}$ and $\mathrm{H}_{2} \mathrm{O}$ environments, it is likely that the differences between studies are due to differences in UTLS temperatures and availability of 

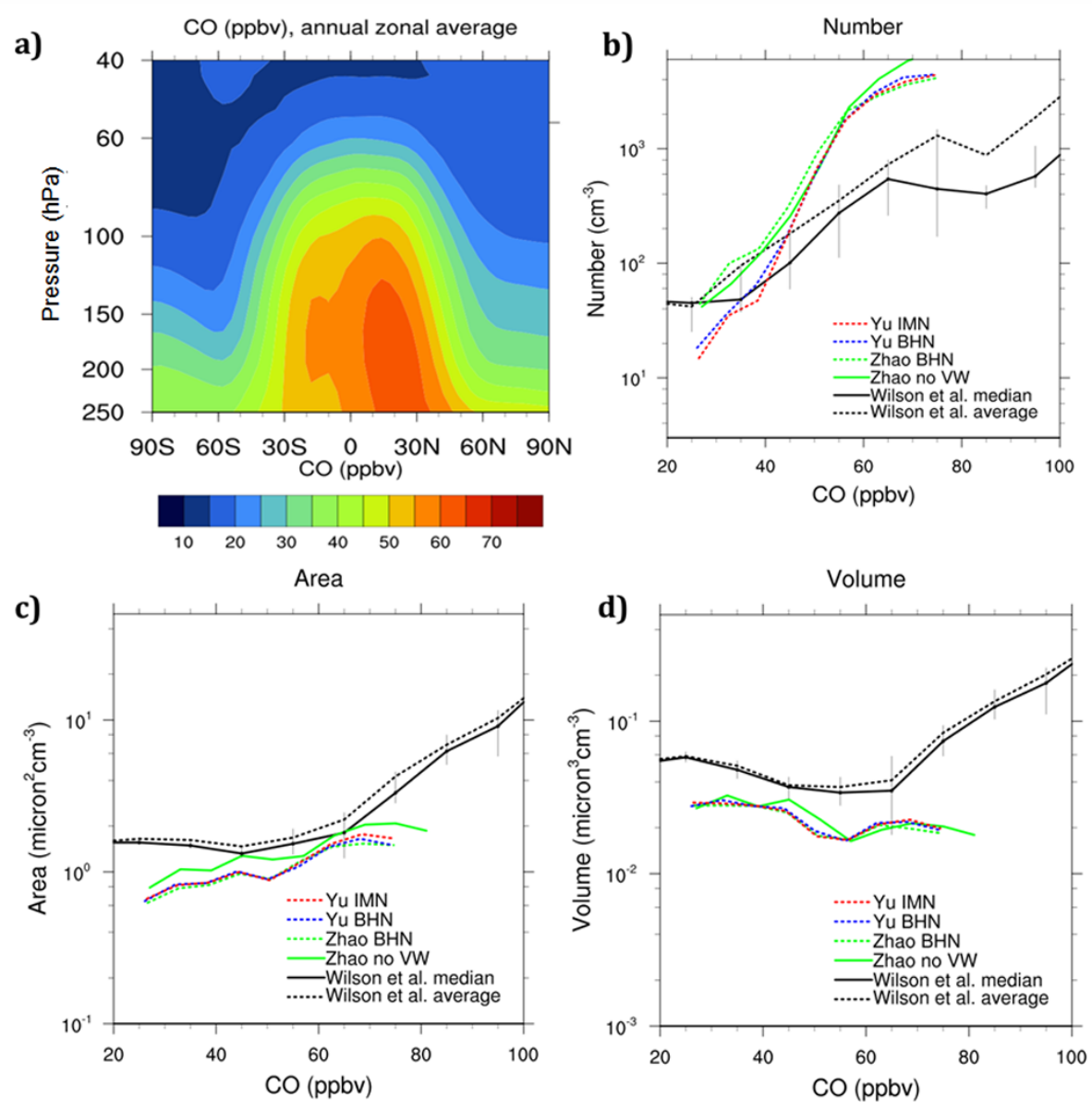

Fig. 11. (a) Calculated CO mixing ratio; annual and zonal average as a function of atmospheric pressure and latitude. (b) Calculated number, (c) Calculated area, and (d) Calculated volume versus CO compared to a compilation of aircraft observations provided by J. C. Wilson and J. M. Reeves. Average (solid) and median (dotted) observations are drawn from Earth Science Project Office Archives database of 2577 data points from 13 flights between January 2004 and August 2007 spanning $3^{\circ} \mathrm{S}$ to $21^{\circ} \mathrm{N}, 78^{\circ} \mathrm{W}$ to $95^{\circ} \mathrm{W}$, and 8 to $19 \mathrm{~km}$ altitude. The particle collector has a lower cutoff of $4 \mathrm{~nm}$ diameter. It is assumed that no water is present on the particles when area and volume are computed. Simulations are annual averages spanning $3^{\circ} \mathrm{S}$ to $21^{\circ} \mathrm{N}, 60$ to $250 \mathrm{hPa}$, and all longitudes, binned into increments of $6 \mathrm{ppbv} \mathrm{CO}$. Simulations include particles with $4.0 \mathrm{~nm}$ dry diameter and higher. The Zhao no VW simulation does not have the Van der Waals correction, while the three nucleation scheme comparisons (Zhao BHN, Yu BHN, and Yu IMN) include the correction.

Table 2. Modeled critical radii and nucleation rates in the UTLS (between 50 and $500 \mathrm{hPa}$ and $50^{\circ} \mathrm{S}$ and $50^{\circ} \mathrm{N}$ ). All calculations are for the annual average of the third simulation year, except for 30-min peak rate, which is the maximum rate found across all 30-min timesteps for the third simulation year. Annual average is the average across all grid boxes in the specified UTLS range. Annual peak rate is for the grid box with the highest annual rate in the specified UTLS range.

\begin{tabular}{lrrrr}
\hline Simulation & $\begin{array}{r}\text { Critical radius } \\
(\mathrm{nm})\end{array}$ & $\begin{array}{r}\text { Annual average } \\
\text { rate }\left(\mathrm{cm}^{-3}\right)\end{array}$ & $\begin{array}{r}\text { Annual peak } \\
\text { rate }\left(\mathrm{cm}^{-3} \mathrm{~s}\right)\end{array}$ & $\begin{array}{r}\text { 30-min peak } \\
\text { rate }\left(\mathrm{cm}^{-3} \mathrm{~s}\right)\end{array}$ \\
\hline Zhao BHN & 0.45 & 53.08 & 5099 & 432279 \\
Yu BHN & 0.72 & 0.50 & 71 & 2587 \\
Yu IMN & 0.72 & 0.75 & 70 & 2761 \\
\hline
\end{tabular}

$\mathrm{H}_{2} \mathrm{SO}_{4}$ and $\mathrm{H}_{2} \mathrm{O}$. Regardless, the present results do suggest that ions produced from cosmic rays may impact nucleation rates in the UTLS to a small degree. Note also that the Zhao
BHN scheme (classical nucleation theory) predicts two orders of magnitude higher rates than the Yu BHN scheme (kinetic nucleation theory), suggesting that the uncertainty 

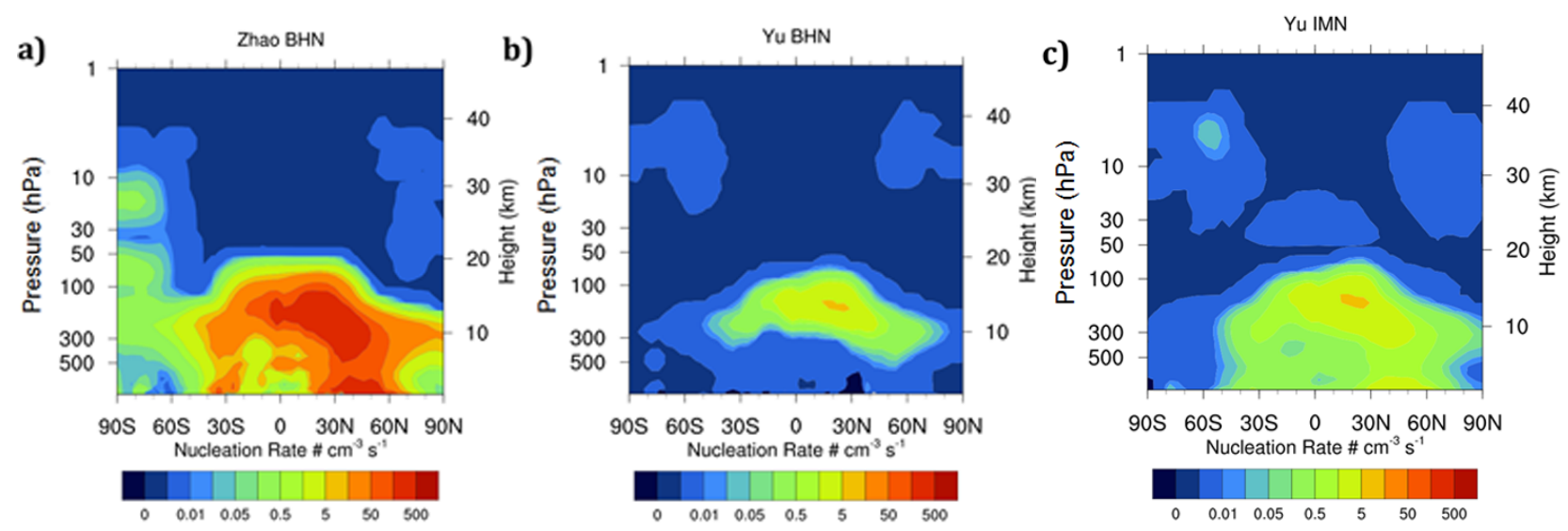

Fig. 12. Calculated nucleation rates; annual and zonal average as a function of atmospheric pressure and latitude. (a) Zhao BHN. (b) Yu BHN. (c) Yu IMN.

associated with BHN computations is much larger than the effects of ions on nucleation in the UTLS. The large differences between BHN schemes have been documented previously (Korhonen et al., 2003; Yu et al., 2010), and can be partially explained by differences in predicted critical radii the Yu schemes predict critical radii that are $60 \%$ larger than the Zhao BHN scheme. The larger sizes of new particles predicted by the Yu schemes partially offsets lower nucleation rates, resulting in a less substantial difference in sulfate mass and number concentration at larger sizes (e.g. Zhao BHN predicts a 100 times higher particle number creation rate from nucleation but only 17 times higher particle mass creation rate). Finally, note that the Yu BHN and Yu IMN lookup tables, designed for tropospheric conditions, were originally found to predict unrealistic nucleation rates in the middle and upper stratosphere due to exceptionally low relative humidities $(<0.1 \%)$ being outside the Table bounds. While setting nucleation to zero if relative humidity was less than the Table minimum resolved much of this issue, it is possible that this approach may predict too little nucleation in certain regions. However, an analysis of the input parameters has found that the tables behave well in the UTLS region and below.

\subsection{Effects of nucleation rates on aerosol size distributions}

Calculated size distributions are compared with data from 56 aircraft flights from a range of NASA field programs summarized by Lee et al. (2003). Size distributions are calculated for three regions: tropical troposphere $(7-17 \mathrm{~km})$, midhigh latitude UTLS (7-13 km), and high-latitude stratosphere $(17-21 \mathrm{~km})$, and the data are separated into series with or without recent new particle formation (NPF). Recent NPF was defined as meeting two conditions: (i) number concentrations with diameter 4-6 nm exceeds that of number con- centration with diameter 6-9 nm, and (ii) number concentrations with diameter $4-9 \mathrm{~nm}$ exceed $1 \mathrm{~cm}^{-3}$. Simulation size bin ranges are selected based on the closest bins available to the size specified in Lee et al. (2003). Calculated 1-day averages of the third year are checked for NPF conditions and segregated into two sets of data (with and without recent NPF). Simulation "data" points include values for 360 days in the third simulation year. The model outputs daily averages, so these criteria will not provide instantaneous indicators of recent NPF. Additionally, since the model output is across the entire year, while the aircraft data are obtained on specific days, differences may be due to temporal variability. A summary of the number of simulation data points considered NPF days and no NPF days is provided in Table 3. All three schemes reported all days were NPF days in the tropical troposphere, most days were NPF days in the high-latitude UTLS, and very few NPF days occurred in the high-latitude stratosphere. Lee et al. reported $16 \%$ of size distributions to be considered NPF events.

Size distributions for each of the three regions are provided in Fig. 13. In the tropical troposphere (Fig. 13a), high numbers of particles are observed and predicted, as expected due to this region being conducive to NPF. Relative differences in number concentrations between the three schemes at the smallest sizes are explained by differences in nucleation rates. All three schemes predict approximately two times too many of the smallest particles, and are missing the observed size mode at $30 \mathrm{~nm}$. It is possible that this discrepancy is due to the lack of other aerosol types in the model. Advection of aged aerosol from other regions could contribute to growth rather than nucleation, reducing the number concentration at the smallest sizes and possibly creating a mode near $30 \mathrm{~nm}$. A similar trend is observed in the mid-high latitude UTLS region where NPF was observed (Fig. 13b); all three of the simulations predict two times too many particles at the smallest sizes. In the mid-high latitude UTLS where NPF 

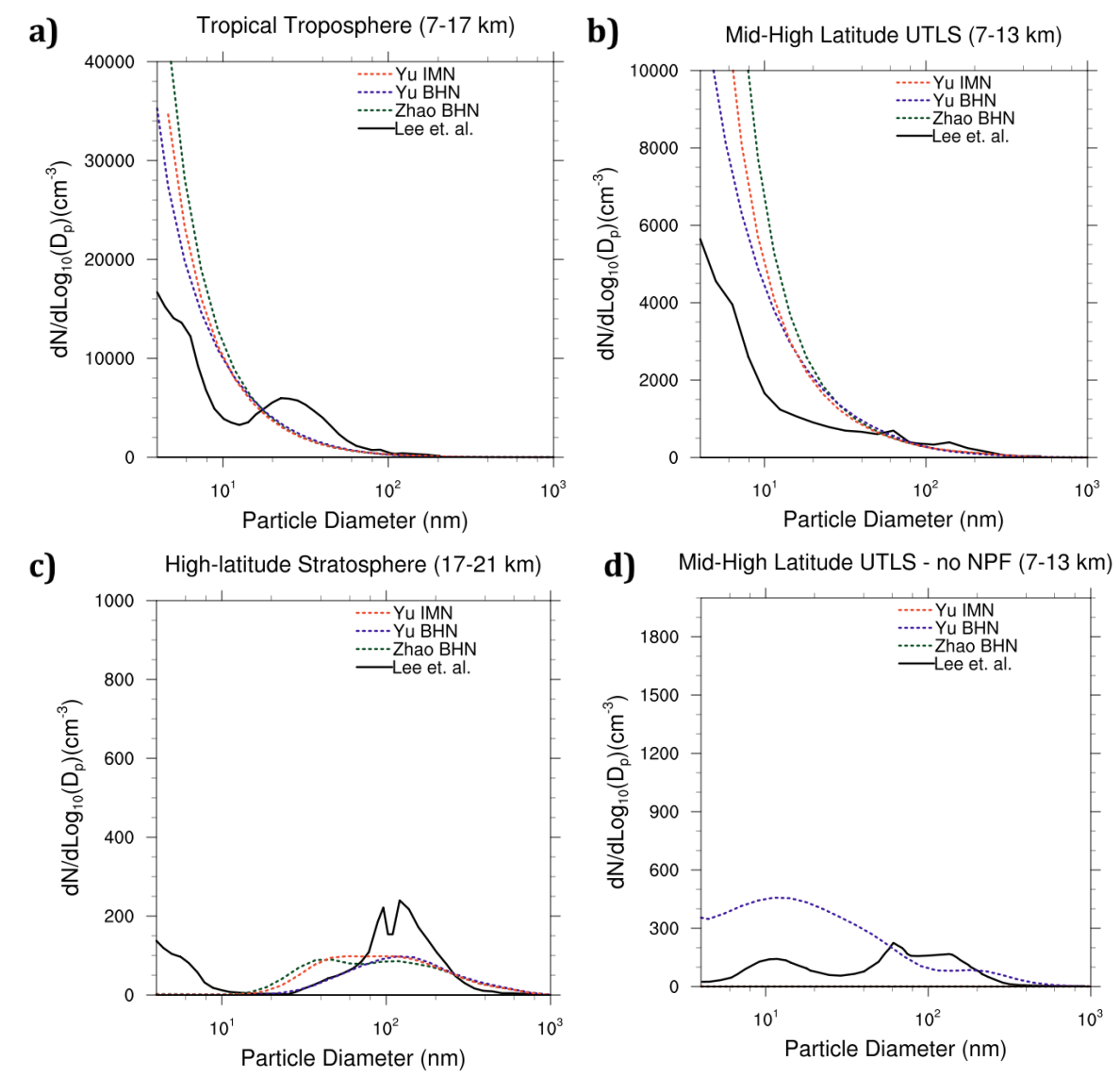

Fig. 13. Size distributions, corrected for STP, for the 3 calculated nucleation schemes compared to observed size distributions from 56 NASA flights between 1998-2000 as reported by Lee et al. (2003). Size distributions when recent NPF was observed at three different regions: (a) tropical troposphere, (b) mid-high latitude UTLS, and (c) high-latitude stratosphere. Observations define recent NPF when two conditions are met: (i) number concentrations with diameter $4-6 \mathrm{~nm}$ exceeding that of number concentration with diameter 6-9 nm, and (ii) number concentrations with diameter $4-9 \mathrm{~nm}$ exceeding $1 \mathrm{~cm}^{-3}$. Simulations were subjected to the same criteria by analyzing daily averages across the third simulation year for all grid boxes within the region. Simulation size bin ranges are selected based on the closest bins available to the size specified in Lee et al. (d) Size distributions in the mid-high latitude UTLS when recent NPF was not observed. Here, only the Yu BHN simulation is plotted because the Zhao BHN and Yu IMN schemes did not predict any days with no NPF.

Table 3. Count and percent of model simulation days that meet conditions for NPF as defined by Lee et al. (2003). Lee et al. reported $16 \%$ of total size distributions to be considered NPF events.

\begin{tabular}{lll|ll|ll}
\hline & \multicolumn{2}{c|}{ Zhao BHN } & \multicolumn{2}{c|}{ Yu BHN } & \multicolumn{2}{c}{ Yu IMN } \\
\cline { 2 - 7 } & Count & $\%$ & Count & $\%$ & Count & $\%$ \\
\hline Tropical Troposphere & $360 / 360$ & $100 \%$ & $360 / 360$ & $100 \%$ & $360 / 360$ & $100 \%$ \\
Mid-High Latitude UTLS & $360 / 360$ & $100 \%$ & $348 / 360$ & $97 \%$ & $360 / 360$ & $100 \%$ \\
High Latitude Stratosphere & $14 / 360$ & $3.9 \%$ & $2 / 360$ & $0.6 \%$ & $4 / 360$ & $1.1 \%$ \\
\hline
\end{tabular}

was not observed (Fig. 13d), only the Yu BHN predicted days with no NPF. This simulation replicates both the $10 \mathrm{~nm}$ and $100 \mathrm{~nm}$ modes that are observed, albeit with a larger $10 \mathrm{~nm}$ mode and a smaller $100 \mathrm{~nm}$ mode. In the high-latitude stratosphere (Fig. 13c), all three schemes reproduce the observed $100 \mathrm{~nm}$ mode, with particle number within a factor of two of that observed. All three schemes predict a broader mode than observed, with the Yu BHN scheme better reproducing the mode at the small end. However, only 14, 2, and four days, respectively for the Zhao BHN, Yu BHN, and Yu IMN schemes met the criteria for stratospheric NPF. When plotting all simulation output regardless of whether the grid cells 

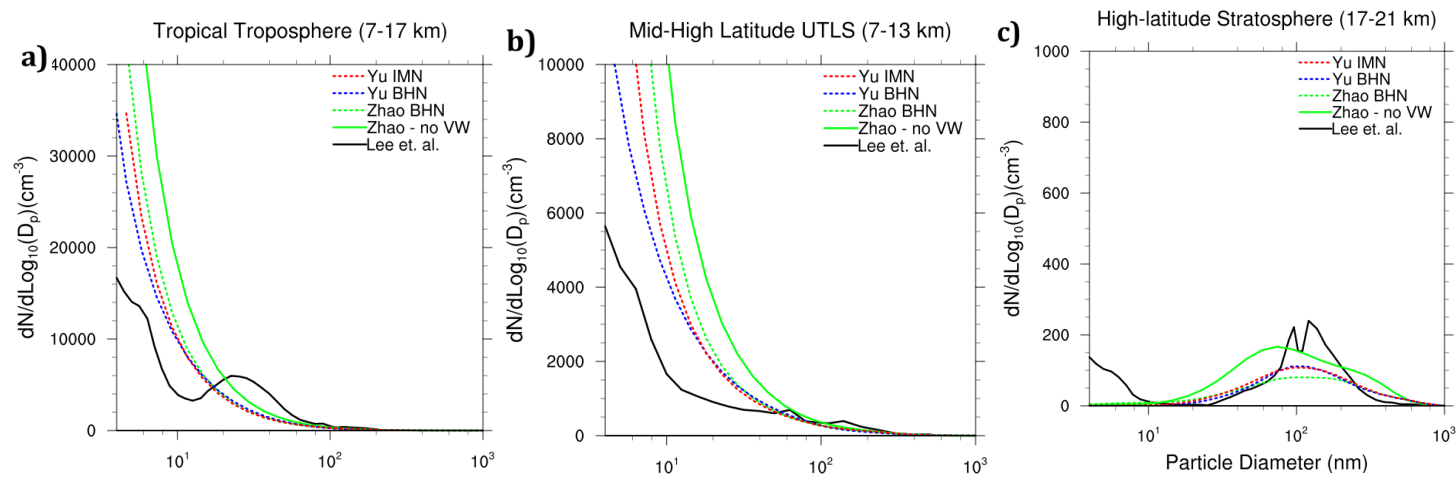

Fig. 14. Same as Fig. 13 except all simulation grid boxes are averaged, regardless of whether they met the criteria for recent NPF.

met the criteria for recent NPF (Fig. 14), all three simulations predict a similar size mode in the stratosphere. In most cases, the three nucleation schemes produce simulations that differ at the smallest sizes due to differing nucleation rates, but become nearly indistinguishable from one another at sizes larger than $10 \mathrm{~nm}$. On the other hand, the Zhao no VW curve has higher number concentrations than any of the nucleation schemes. This reinforces the conclusion that coagulation, not nucleation is the dominant process determining aerosol number at atmospherically relevant sizes.

\subsection{Effects of nucleation rate on aerosol number concentrations}

We illustrate vertical profiles of calculated sulfate number concentration $(>8 \mathrm{~nm}$ ) compared to aircraft observations (Borrmann et al., 2010; Brock et al., 1995) in Fig. 10. All three simulations with varying nucleation rate correlate very well with observations in both the tropics (Fig. 10a) and extratropics (Fig. 10b). Although nucleation rates differ by up to two orders of magnitude, there is very little difference in number concentration of particles $>8 \mathrm{~nm}$. Likewise, comparisons of aerosol number $(>4 \mathrm{~nm}$ ) versus $\mathrm{CO}$ suggest differences due to nucleation schemes (Fig. 11b), but aerosol area (Fig. 11c) and volume (Fig. 11d) are virtually unaffected by nucleation scheme. Again, this suggests that the choice of nucleation scheme is nearly irrelevant compared to the impacts of coagulation at atmospherically relevant sizes.

Similar trends are seen when comparing calculated zonal-averaged number concentrations in the upper troposphere to aircraft observations from the CARIBIC campaign (Heintzenberg et al., 2003). In the 4-12 nm size range (Fig. 15b), predicted number concentrations vary by a factor of 5 between nucleation simulations, with the highest nucleation rates (Zhao BHN) being associated with the highest number concentration. But at sizes above $12 \mathrm{~nm}$ (Fig. 15c and d), the differences in number concentration between the nucleation schemes become muted as coagulation become dominant. When comparing the model to the observations, however, in this comparison there are numerous discrepancies. Observed number concentrations peak near the equator while the simulations peak near industrial latitudes. In the 4-12 nm size range (Fig. 15b), both observations and simulations peak at about $20000 \mathrm{~cm}^{-3}$ Standard Temperature and Pressure (STP) $(273 \mathrm{~K}, 1013.25 \mathrm{hPa})$, while at the larger sizes the simulations underpredict number concentration by up to an order of magnitude. The discrepancy at larger sizes may be due to the model treating only sulfates and not other types of aerosols, such as organics or biomass burning products. The underprediction could also be due to uncertainties in the emission of gaseous precursors, particularly dimethylsulfide or volcanic emissions, which we do not have in our model. It could also be due to the model not including other types of nucleation near the surface, which is known to be important in this region (Kazil et al., 2010). Any of these discrepancies may be due to a mismatch between the spatial scale of the observations and simulations. The observations are taken across a flight path at a specific altitude, latitude, and longitude, while the model simply averages a region over the entire altitude and latitude range. A contour plot of calculated number concentration for the Zhao BHN case as a function of latitude and longitude between 216$316 \mathrm{hPa}$ (Fig. 15a) shows that number concentration can vary up to two orders of magnitude at the same altitude across the globe.

\subsection{Effect of nucleation rate on effective radius and extinction}

Vertical profiles of effective radii and extinctions for each of the three calculated nucleation schemes are compared to SAGE II satellite observations in Figs. 8 and 16. All three nucleation schemes yield essentially identical results. Effective radius is important for radiative forcing, while extinction is proportional to surface area, which is important to heterogeneous chemistry. Hence the choice of nucleation rate should not be important to radiative forcing or atmospheric chemistry. 

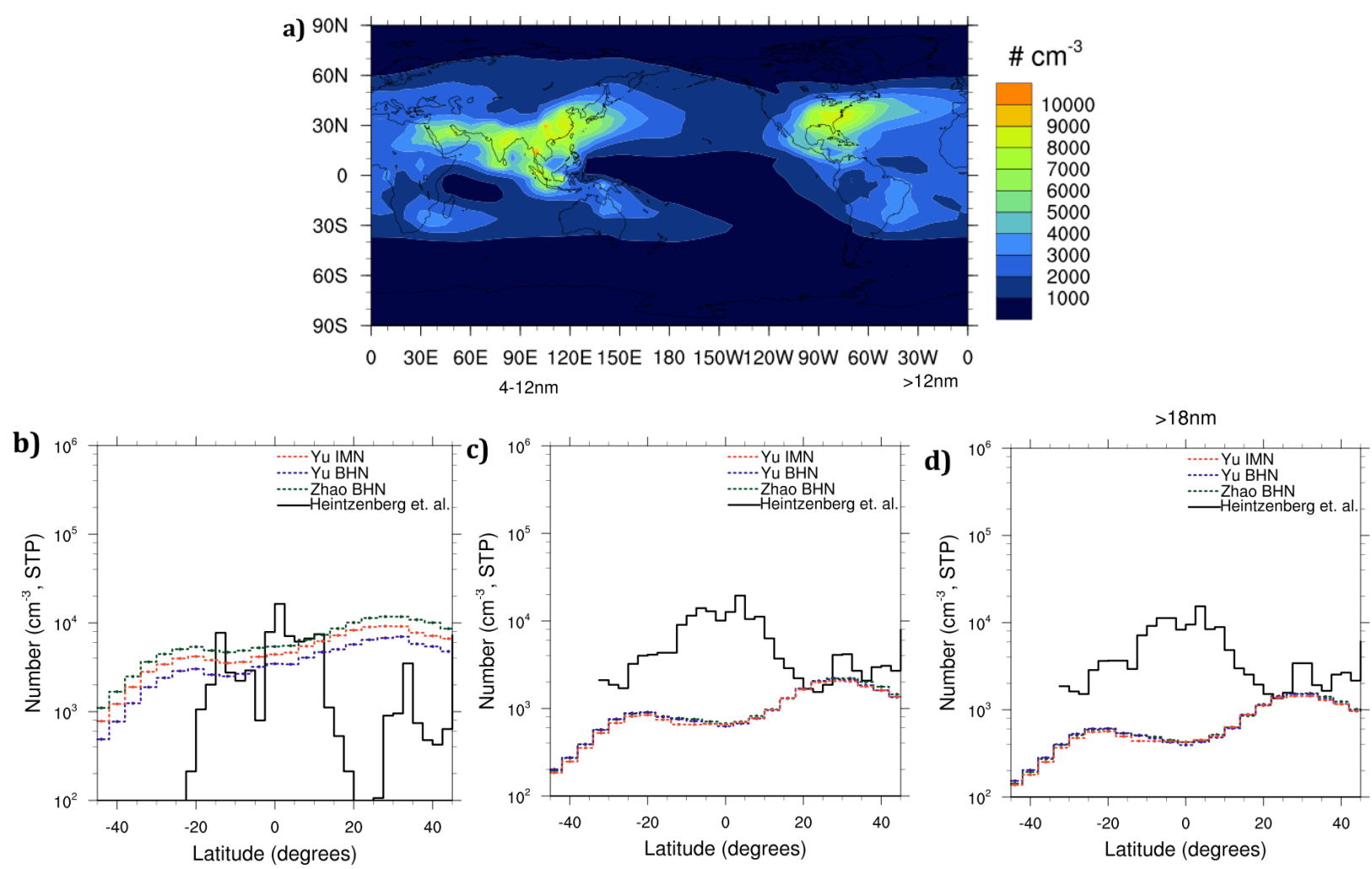

Fig. 15. (a) Calculated number concentration greater than $4 \mathrm{~nm}$ dry diameter as a function of latitude and longitude, using an annual average of the Zhao BHN simulation between $216-316 \mathrm{hPa}$ (approximately $8.5-11.3 \mathrm{~km}$ ). Comparison of zonal-average number concentrations to aircraft observations as a function of latitude over the altitude region $8.5-11.3 \mathrm{~km}$ for three particle diameter ranges: (b) 4-12 nm, (c) $>12 \mathrm{~nm}$, and (d) $>18 \mathrm{~nm}$. Observations are averages of 6 commercial flights between Germany, Namibia, and South Africa in May, July, and December 2000 (Heintzenberg et al., 2003). Simulations are annual and zonal averages at the bin ranges closest to the dry diameters specified $(4.0 \mathrm{~nm}, 12.8 \mathrm{~nm}$, and $16.2 \mathrm{~nm}$ diameters, respectively).
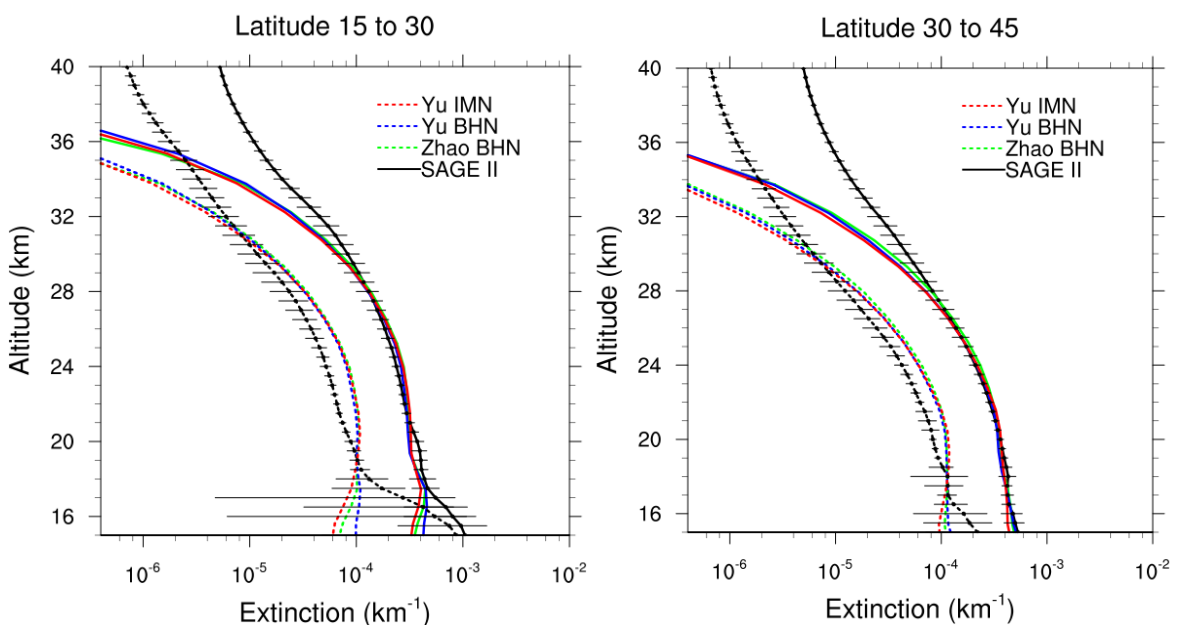

Fig. 16. Calculated sulfate extinctions for the three simulations compared to SAGE II at two wavelengths ( $525 \mathrm{~nm}$; solid lines, and $1024 \mathrm{~nm}$; dotted lines) in the latitude regions specified. 


\section{Conclusions}

We have implemented a three-dimensional general circulation model with sulfur chemistry and sectional aerosol microphysics (WACCM/CARMA). Three nucleation schemes are available in this model: two BHN schemes - one based on classical nucleation theory (Zhao BHN) and one based on kinetic nucleation theory lookup tables (Yu BHN) - as well as an IMN scheme look-up Table (Yu IMN). The two Yu schemes often are found to be out of the Table limits in the middle stratosphere and above due to limits on boundary conditions of Table inputs; this problem was mostly resolved by setting nucleation to zero if relatively humidity is less than the Table minimum value, but the tables should be used with caution in these regions. Further thermodynamic data are needed to extend the Yu schemes into dry stratospheric conditions $(\mathrm{RH}<0.1 \%)$. Calculations suggest that ion-mediated nucleation rates in the UTLS are $25 \%$ higher than binary only, consistent with some studies (e.g. Kazil et al., 2010) but different from others (e.g., Yu et al., 2010). However, the two binary schemes vary by two orders of magnitude, consistent with other studies (Korhonen et al., 2003; Yu et al., 2010). More importantly, it is found that coagulation, not nucleation, controls number concentration at sizes greater than approximately $10 \mathrm{~nm}$ in the UTLS and the middle and upper stratosphere. The dominance of coagulation over other microphysical processes is consistent with other recent work using microphysical models; Pierce and Adams (2009) found coagulation to be more important than nucleation in tropospheric studies, and Timmreck et al. (2010) found coagulation to drive stratospheric particle sizes from the eruption of Mount Toba to much larger values than previously assumed. Lee et al. (2003) suggested that ion nucleation was important in the UTLS, on the basis of their ability to match observed size distributions with a model based on ion clusters. In contrast, we find that identical size distributions are produced for each type of nucleation, due to the dominance of coagulation. Hence fitting the size distribution is not diagnostic of the type of nucleation occurring (binary or ion). Unfortunately, the rate of nucleation is not easily determined from data either, because all of the particle properties for particles larger than $10 \mathrm{~nm}$ are not altered even for two-order-of-magnitude changes in the nucleation rate.

We compared our calculations to observations from the tropopause to the mid-stratosphere. Above about $30 \mathrm{~km}$, the model underpredicts SAGE extinctions, which we suggest is due to the importance of micrometeorites, as observed by Hervig et al. (2009). We also found that including Van der Waals forces improved the model calculations for the numbers of particles in the UTLS. We conclude that this model contains the sulfate microphysical processes needed for simulations in the UTLS, and that the properties of particles with sizes relevant to climate, cloud physics and heterogeneous chemistry are not sensitive to the details of the nucleation scheme or to the presence or absence of ion nucleation.
Acknowledgements. We thank Charles Bardeen for help coupling CARMA and CAM. We thank V. Lynn Harvey for help with the SAGE II extinction data. We thank Ryan Neely for help converting Deshler balloon data. This work was supported by NSF Awards ATM-0856007 and AGS-0942106, NASA Award NNX09AK71G, and NASA GSRP Fellowship NNX-09AM38H. NCAR is sponsored by the National Science Foundation.

Edited by: R. Krejci

\section{References}

Alam, M. K.: The effect of Van der Waals and viscous forces on aerosol coagulation, Aerosol Sci. Technol., 6, 41-52, doi:10.1080/02786828708959118, 1987.

Arnold, F., Fabian, R., and Joos, W.: Measurements of the height variation of sulfuric-acid vapor concentrations in the stratosphere, Geophys.Res. Lett., 8, 293-296, 1981.

Ayers, G. P., Gillett, R. W., and Gras. J. L.: On the vapor-pressure of sulfuric acid, Geophys. Res. Lett., 7, 433-436, 1980.

Bardeen, C. G., Toon, O. B., Jensen, E. J., Marsh, D. R., and Harvey, V. L.: Numerical simulations of the three-dimensional distribution of meteoric dust in the mesosphere and upper stratosphere, J. Geophys. Res., 113, D17202, doi:10.1029/2007jd009515, 2008.

Bardeen, C. G., Toon, O. B., Jensen, E. J., Hervig, M. E., Randall, C. E., Benze, S., Marsh, D. R., and Merkel, A.: Numerical simulations of the three-dimensional distribution of polar mesospheric clouds and comparisons with Cloud Imaging and Particle Size (CIPS) experiment and the Solar Occultation For Ice Experiment (SOFIE) observations, J. Geophys. Res., 115, D10204, doi:10.1029/2009JD012451, 2010.

Barth, M. C., Rasch, P. J., Kiehl, J. T., Benkovitz, C. M., and Schwartz, S. E.: Sulfur chemistry in the National Center for Atmospheric Research Community Climate Model: Description, evaluation, features, and sensitivity to aqueous chemistry, J. Geophys. Res.-Atmospheres, 105, 1387-1415, 2000.

Bates, T. S., Huebert, B., Gras, J., Griffiths, F., and Durkee, P.: The International Global Atmospheric Chemistry (IGAC) Project's First Aerosol Characterization Experiment (ACE-1): Overview, J. Geophys. Res., 103, 16297-16318, 1998.

Blitz, M. A., McKee, K. W., and Pilling, M. J.: Temperature dependence of the reaction of $\mathrm{OH}$ with $\mathrm{SO}, \mathrm{P}$. Combust. Inst., 28, 2491-2497, 2000.

Blitz, M. A., Hughes, K. J., and Pilling, M. J.: Determination of the high-pressure limiting rate coefficient and the enthalpy of reaction for $\mathrm{OH}+\mathrm{SO}_{2}$, J. Phys. Chem. A, 101, 1971-1978, 2003.

Borrmann, S., Kunkel, D., Weigel, R., Minikin, A., Deshler, T., Wilson, J. C., Curtius, J., Volk, C. M., Homan, C. D., Ulanovsky, A., Ravegnani, F., Viciani, S., Shur, G. N., Belyaev, G. V., Law, K. S., and Cairo, F.: Aerosols in the tropical and subtropical UT/LS: in-situ measurements of submicron particle abundance and volatility, Atmos. Chem. Phys., 10, 5573-5592, doi:10.5194/acp-10-5573-2010, 2010.

Brock, C. A., Hamill, P., Wilson, J. C., Jonsson, H. H., and Chan, K. R.: Particle formation in the upper tropical troposphere A source of nuclei for the stratospheric aerosol, Science, 270, 1650-1653, 1995. 
Brunning, J. and Stief, L. J.: Kinetic studies of the reaction of the SO radical with $\mathrm{NO}_{2}$ and $\mathrm{ClO}$ from 210 to $363 \mathrm{~K}$, J. Chem. Phys., 84, 4371-4377, 1986a.

Brunning, J. and Stief, L. J.: Rate constant for the reaction SO + BrO -> SO2 + Br, J. Chem. Phys., 85, 2591, doi:10.1063/1.451066, 1986b.

Burkholder, J. B. and McKeen, S.: UV absorption cross-section for SO3, Geophys. Res. Lett., 24, 3201-3204, 1997.

Chan, T. W. and Mozurkewich, M.: Measurement of the coagulation rate constant for sulfuric acid particles as a function of particle size using tandem differential mobility analysis, J. Aerosol Sci., 32, 321-339, 2001.

Cheng, B. M. and Lee, Y. P.: Rate constant of $\mathrm{OH}+$ OCS reaction over the temperature range 255-483K, Int. J. Chem. Kinet., 18, 1303-1314, 1986.

Chu, W. P., McCormick, M. P., Lenoble, J., Brogniez, C., and Pruvost, P.: SAGE II inversion algorithm, J. Geophys. Res., 94, 8339-8351, 1989.

Clarke, A. D.: Atmospheric nuclei in the Pacific midtroposphere - their nature, concentration, and evolution, J. Geophys. Res.Atmos., 98, no. D11, 20633-20647, 1993.

Clarke, A. D. and Kapustin, V. N.: A Pacific aerosol survey. part I: A decade of data on particle production, transport, evolution, and mixing in the troposphere, J. Atmos. Sci., 52, 363-382, 2002.

Clyne, M. A. A. and MacRobert, A. J.: Kinetic-studies of freeradical reactions by mass-spectrometry, Int. J. Chem. Kinet., 13, 187-197, 1981.

Clyne, M. A. A. and Townsend, L. W.: Rate constant measurements for rapid reactions of ground-state sulfur 3P4(P-3(J)) atoms, Int. J. Chem. Kinet. Symp., 1, 73-84, 1975.

Coffman, D. J. and Hegg, D. A.: A preliminary study of the effect of ammonia on particle nucleation in the marine boundary layer, J. Geophys. Res., 100, 7147-7160, 1995.

Colella, P. and Woodward, P. R.: The piecewise parabolic method (PPM) for gas-dynamical simulations, J. Comput. Phys., 54, 174-201, 1984.

Crutzen, P. J.: Albedo enhancement by stratospheric sulfur injections: A contribution to resolve a policy dilemma?, Climatic Change, 77, 211-219, 2006.

Curtius, J., Sierau, B., Arnold, F., de Reus, M., Strom, J., Scheeren, H. A., and Lelieveld, J.: Measurement of aerosol sulfuric acid 2. Pronounced layering in the free troposphere during the second Aerosol Characterization Experiment (ACE 2), J. Geophys. Res.Atmos., 106, 31975-31990, 2001.

Davis, D. D., Klemm, R. B. and Pilling, M.: A flash photolysis-resonance fluorescence kinetics study of groundstate sulfur atoms: I. Absolute rate parameters for reaction of $\mathrm{S}\left({ }^{3} \mathrm{P}\right)$ with $\mathrm{O}_{2}\left({ }^{3} \Sigma\right)$, Int. J. Chem. Kinet., 4, 367-382, doi:10.1002/kin.550040402, 1972.

Deshler, T., Hervig, M. E., Hofmann, D. J., Rosen, J. M., and Liley, J. B.: Thirty years of in-situ stratospheric aerosol size distribution measurements from Laramie, Wyoming (41N), using balloon-borne instruments, J. Geophys. Res., 108, 4167, doi:10.1029/2002JD002514, 2003.

Eisele, F. L., Lovejoy, E. R., Kosciuch, E., Moore, K. F., Mauldin III, R. L., Smith, J. N., McMurry, P. H., and Iida, K.: Negative atmospheric ions and their potential role in ion-induced nucleation, J. Geophys. Res., 111, D04305, doi:10.1029/2005JD006568, 2006.
Fan, T. and Toon, O. B.: Modeling sea-salt aerosol in a coupled climate and sectional microphysical model: mass, optical depth and number concentration, Atmos. Chem. Phys., 11, 4587-4610, doi:10.5194/acp-11-4587-2011, 2011.

Flood, H.: Droplet formation in oversaturated ethanol-water vapour mixtures, Zeit, Chem. Phys., 170, 286-294, 1934.

Froyd, K. D., Murphy, D. M., Sanford, T. J., Thomson, D. S., Wilson, J. C., Pfister, L., and Lait, L.: Aerosol composition of the tropical upper troposphere, Atmos. Chem. Phys., 9, 4363-4385, doi:10.5194/acp-9-4363-2009, 2009.

Fuchs, N. A.: The Mechanics of Aerosols, Pergamon, New York, USA, 1964.

Garcia, R. R., Marsh, D. R., Kinnison, D. E., Boville, B. A., and Sassi, F.: Simulation of secular trends in the middle atmosphere, 1950-2003, J. Geophys. Res.-Atmos., 112(D9), D09301, doi:10.1029/2006JD007485, 2007.

Giauque, W. F., Hornung, E. W., Kunzler, J. E., and Rubin, T. R.: The thermodynamic properties of aqueous sulfuric acid solutions and hydrates from 15-degrees-K to 300-degrees-K, J. Amer. Chem. Soc., 82, 62-70, 1960.

Hamill, P., Toon, O. B., and Kiang, C. S.: Microphysical processes affecting stratospheric aerosol particles, J. Atmos. Sci., 34, 1104-1119, 1977.

Hanson, D. R. and Lovejoy, E. R.: Measurement of the thermodynamics of the hydrated dimer and trimer of sulfuric acid, J. Phys. Chem. A-Letters, 110, 9525-9528, 2006.

Heckendorn, P., Weisenstein, D., Fueglistaler, S., Luo, B. P., Rozanov, E. Schraner, M., Thomason, L. W., and Peter, T.: The impact of geoengineering aerosols on stratospheric temperature and ozone, Environ. Res. Lett., 4, 045108, doi:10.1088/17489326/4/4/045108, 2009.

Heintzenberg, J., Hermann, M., and Theiss, D.: Out of Africa: High aerosol concentrations in the upper troposphere over Africa, Atmos. Chem. Phys., 3, 1191-1198, doi:10.5194/acp-3-1191-2003, 2003.

Hervig, M. E., Gordley, L. L., Deaver, L. E., Siskind, D. E., Stevens, M. H., Russell III, J. M., Bailey, S. M., Megner, L., and Bardeen, C. G.: First satellite observations of meteoric smoke in the middle atmosphere, Geophys. Res. Lett., 36, L18805, doi:10.1029/2009GL039737, 2009.

Hoell, J. M., Davis, D. D., Jacob, D. J., Rodgers, M. O., Newell, R. E., Fuelberg, H. E., McNeal, R. J., Raper, J. L., and Bendura, R. J.: Pacific Exploratory Mission in the tropical Pacific: PEM-Tropics A, August-September 1996, J. Geophys. Res., 104, 5567-5583, 1999.

Hofman, D. J. and Solomon, S.: Ozone destruction through heterogeneous chemistry following the eruption of El Chichon, J. Geophys. Res.-Atmos., 94, 5029-5041, 1989.

Huang, D. D., Seinfeld, J. H., and Marlow, W. H.: BGK equation solution of coagulation for large Knudsen number aerosols with a singular attractive contact potential, J. Colloid Interf. Sci., 140, 258-276, doi:10.1016/0021-9797, 1990.

Hunten, M. D., Turco, R. P., and Toon, O. B.: Smoke and dust particles of meteoric origin in the mesosphere and stratosphere, J. Atmos. Sci., 37, 1342-1357, 1980.

Jensen, E. J., Toon, O. B., Selkirk, H. B., Spinhirne, J. D., and Schoeberl, M. R.: On the formation and persistence of subvisible cirrus clouds near the tropical tropopause, J. Geophys. Res., 101, 21361-21375, 1996. 
Jourdain, J. L., Le Bras, G., and Combourieu, J.: Kinetic study of reactions of 1,1,1 trifluoro-2 chloroethane with chlorine atoms and oxygen atoms, J. Chim. Phys., 75, 318-323, 1978.

Kanawade, V. and Tripathi, S. N.: Evidence for the role of ion-induced particle formation during an atmospheric nucleation event observed in Tropospheric Ozone Production about the Spring Equinox (TOPSE), J. Geophys. Res.-Atmos., 111, D02209, doi:10.1029/2005JD006366, 2006.

Kazil, J., Lovejoy, E. R., Jensen, E. J., and Hanson, D. R.: Is aerosol formation in cirrus clouds possible?, Atmos. Chem. Phys., 7, 1407-1413, doi:10.5194/acp-7-1407-2007, 2007.

Kazil, J., Stier, P., Zhang, K., Quaas, J., Kinne, S., O’Donnell, D., Rast, S., Esch, M., Ferrachat, S., Lohmann, U., and Feichter, J.: Aerosol nucleation and its role for clouds and Earth's radiative forcing in the aerosol-climate model ECHAM5-HAM, Atmos. Chem. Phys., 10, 10733-10752, doi:10.5194/acp-1010733-2010, 2010.

Kinnison, D. E., Brasseur, G. P., Walters, S., Garcia, R. R., Marsh, D. R., Sassi, F., Harvey, V. L., Randall, C. E., Emmons, L., Lamarque, J. F., Hess, P., Orlando, J. J., Tie, X. X., Randel, W., Pan, L. L, Gettelman, A., Granier, C., Diehl, T., Niemeier, U., and Simmons, A. J.: Sensitivity of chemical tracers to meteorological parameters in the MOZART-3 chemical transport model, J. Geophys. Res., 112, D20302, doi:10.1029/2006JD007879, 2007.

Korhonen, H., K., Lehtinen, E. J., Pirjola, L., Napari, J., Vehkamäki, H., Noppel, M., and Kulmala, M.: Simulation of atmospheric nucleation mode: A comparison of nucleation models and size distribution representations, J. Geophys. Res., 108, doi:10.1029/2002JD003305, 2003.

Kulmala, M. and Laaksonen, A.: Binary nucleation of water sulfuric-acid system - comparison of classical-theories with different $\mathrm{H}_{2} \mathrm{SO}_{4}$ saturation vapor-pressures, J. Chem. Phys., 93, 696-701, 1990.

Lamarque, J.-F., Bond, T. C., Eyring, V., Granier, C., Heil, A., Klimont, Z., Lee, D., Liousse, C., Mieville, A., Owen, B., Schultz, M. G., Shindell, D., Smith, S. J., Stehfest, E., Van Aardenne, J., Cooper, O. R., Kainuma, M., Mahowald, N., McConnell, J. R., Naik, V., Riahi, K., and van Vuuren, D. P.: Historical (18502000) gridded anthropogenic and biomass burning emissions of reactive gases and aerosols: methodology and application, Atmos. Chem. Phys., 10, 7017-7039, doi:10.5194/acp10-7017-2010, 2010.

Lee, S.-H., Reeves, J. M., Wilson, J. C., Hunton, D. E., Viggiano, A. A., Miller, T. M., Ballenthin, J. O., and Lait, L. R.: Particle formation by ion induced nucleation in the upper troposphere and lower stratosphere, Science, 301, 1886-1889, 2003.

Lin, S. J. and Rood, R. B: Multidimensional flux-form semiLagrangian transport schemes, Mon. Weather Rev., 124, 20462070, 1996.

Lin, S. J. and Rood, R. B.: An explicit flux-form semi-Lagrangian shallow-water model on the sphere, Q. J. R. Meteorol. Soc., 123, 2477-2498, 1997.

Lin, J. S. and Tabazadeh, A.: A parameterization of an aerosol physical chemistry model for the $\mathrm{NH}_{3} / \mathrm{H}_{2} \mathrm{SO}_{4} / \mathrm{HNO}_{3} / \mathrm{H}_{2} \mathrm{O}$ system at cold temperatures, J. Geophys. Res.-Atmos., 106, 4815-4829, 2001.

Lovejoy, E. R., Hanson, D. R., and Huey, L. G.: Kinetics and products of the gas-phase reaction of $\mathrm{SO}_{3}$ with water, J. Phys. Chem.,
100, 19911-19916, 1996.

Lovejoy, E. R., Curtius, J., and Froyd, K. D.: Atmospheric ioninduced nucleation of sulfuric acid and water, J. Geophys. Res., 109, D08204, doi:10.1029/2003JD004460, 2004.

Lucas, D. D. and Prinn, R. G.: Tropospheric distributions of sulfuric acid-water vapor aerosol nucleation rates from dimethylsulfide oxidation, Geophys. Res. Lett., 30, 2136, doi:10.1029/2003GL018370, 2003.

Mills, M. J., Toon, O. B., Vaida, V., Hintze, P. E., Kjaergaard, H. G., Schofield, D. P., and Robinson, T. W.: Photolysis of sulfuric acid vapor by visible light as a source of the polar stratospheric CN layer, J. Geophys. Res., 110, D08201, doi:10.1029/2004JD005519, 2005.

Mills, M. J., Toon, O. B., Turco, R. P., Kinnison, D. E., and Garcia, R. R.: Massive global ozone loss predicted following regional nuclear conflict, PNAS, 105(14), 5307-5312, doi:10.1073/pnas.0710058105, 2008.

Molina, L. T. and Molina, M. J.: UV absorption cross-sections of $\mathrm{HO}_{2} \mathrm{NO}_{2}$ vapor, J. Photochem., 15, 97-108, 1981.

Murphy, D. M., Cziczo, D. J., Hudson, P. K., and Thomson, D. S.: Carbonaceous material in aerosol particles in the lower stratosphere and tropopause region, J. Geophys. Res., 112, D04203, doi:10.1029/2006JD007297, 2007.

Okabe, H.: In Photochemistry of Small Molecules, 248-249, John Wiley and Sons Inc., New York, USA, 1978.

Palmer, K. F. and Williams, D.: Optical constants of sulfuric acid; Application to the clouds of Venus?, Appl. Optics, 14, 208-219, 1975.

Pierce, J. R. and Adams, P. J.: Can cosmic rays affect cloud condensation nuclei by altering new particle formation rates?, Geophys. Res. Lett., 36, L09820, doi:10.1029/2009GL037946, 2009.

Rasch, P. J., Tilmes, S., Turco, R. P., Robock, A., Oman, L., Chen, C., Stenchikov, G. L., and Garcia, R. R.: An overview of geoengineering of climate using stratospheric sulphate aerosols, Philos. T. Roy. Soc. A, 366, 4007-4037, 2008.

Reiner, T. and Arnold, F.: Stratospheric $\mathrm{SO}_{3}$ : Upper limits inferred from ion composition measurement: Implications for $\mathrm{H}_{2} \mathrm{SO}_{4}$ and aerosol formation, Geophys. Res. Lett., 24, 1751-1754, 1997.

Reiss, H.: The kinetics of phase transitions in binary systems, J. Chem. Phys., 18, 840-848, 1950.

Robock, A., Oman, L, and Stenchikov, G. L.: Regional climate responses to geoengineering with tropical and Arctic $\mathrm{SO}_{2}$ injections, J. Geophys. Res.-Atmos., 113, D16101, doi:10.1029/2008JD010050, 2008.

Ross, M., Mills, M., and Toohey, D.: Potential climate impact of black carbon emitted by rockets, Geophys. Res. Lett., 37, L24810, doi:10.1029/2010GL044548, 2010.

Sabinina, A. L. and Terpugow, L.: Die oberflachenspannung de systems schwefelsaure-wasser, Z. Phys. Chem. A, 173, 237-241, 1935.

Sander, S. P., Finlayson-Pitts, B. J., Friedl, R. R., Golden, D. M., Huie, R. E., Keller-Rudek, H., Kolb, C. E., Kurylo, M. J., Molina, M. J., Moortgat, G. K., Orkin, V. L, Ravishankara, A. R., and Wine, P. H.: Chemical Kinetics and Photochemical Data for Use in Atmospheric Studies, Evaluation Number 15, JPL Publication 06-2, Jet Propulsion Laboratory, Pasadena, USA, 2006.

Schlager, H. and Arnold, F.: Balloon-borne composition measurements of stratospheric negative-ions and inferred sulfuric- 
acid vapor abundances during the Map-Globus 1983 campaign, Planet. Space Sci., 35, 693-701, 1987.

Schmidt-Ott, A. and Burtscher, H.: The effect of Van der Waals forces on aerosol coagulation, J. Colloid Interf. Sci., 89(2), 353357, doi:10.1016/0021-9797(82)90187-4, 1982.

Smith, S. J., van Aardenne, J., Klimont, Z., Andres, R. J., Volke, A., and Delgado Arias, S.: Anthropogenic sulfur dioxide emissions: 1850-2005, Atmos. Chem. Phys., 11, 1101-1116, doi:10.5194/acp-11-1101-2011, 2011.

Snow-Kropla, E. J., Pierce, J. R., Westervelt, D. M., and Trivitayanurak, W.: Cosmic rays, aerosol formation and cloudcondensation nuclei: sensitivities to model uncertainties, Atmos. Chem. Phys., 11, 4001-4013, doi:10.5194/acp-11-4001-2011, 2011.

Su, L. and Toon, O. B.: Saharan and Asian dust: similarities and differences determined by CALIPSO, AERONET, and a coupled climate-aerosol microphysical model, Atmos. Chem. Phys., 11, 3263-3280, doi:10.5194/acp-11-3263-2011, 2011.

Tabazadeh, A., Toon, O. B., Clegg, S. L., and Hamill, P.: A new parameterization of $\mathrm{H}_{2} \mathrm{SO}_{4} / \mathrm{H}_{2} \mathrm{O}$ aerosol composition: Atmospheric implications, Geophys. Res. Lett., 24, 1931-1934, 1997.

Thornton, D. C., Bandy, A. R., Blomquist, B. W., Driedger, A. R., and Wade, T. P.: Sulfur dioxide distribution over the Pacific Ocean 1991-1996, J. Geophys. Res., 104, 5845-5854, 1999.

Timmreck, C., Graf, H.-F., Lorenz, S. J., Niemeier, U., Zanchettin, D., Matei, D., Jungclaus, J. H., and Crowley, T. J.: Aerosol size confines climate response to volcanic super-eruptions, Geophys. Res. Lett., 37, L24705, doi:10.1029/2010GL045464, 2010.

Toon, O. B., Turco, R. P., Westphal, D., Malone, R., and Liu, M. S.: A multidimensional model for aerosols - description of computational analogs, J. Atmos. Sci., 45, 2123-2143, 1988.

Usoskin, I. G., Desorgher, L., Velinov, P., Storini, M., Fluckiger, E. O., Butikofer, R., Kovaltsov, G. A.: Ionization of the earth's atmosphere by solar and galactic cosmic rays, Acta Geophys., 57, 88-101, 2009.

Vaida, V., Kjaergaard, H. G., Hintze, P. E., and Donaldson, D. J.: Photolysis of sulfuric acid vapor by visible solar radiation, Science, 299, 1566-1568, 2003.

Viggiano, A. A. and Arnold, F.: Extended sulfuric acid vapor concentration measurements in the stratosphere, Geophys. Res. Lett., 8, 583-586, 1981.

Wang, P. H., Minnis, P., and Yue, G. K.: Extinction coefficient

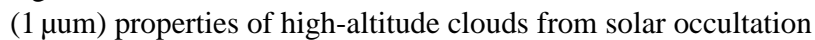
measurements (1985-1990): Evidence of volcanic aerosol effect, J. Geophys. Res., 100, 3181-3199, 1995.

Wang, P. H., Kent, G. S., and McCormick, M. P.: Retrieval analysis of aerosol-size distribution with simulated extinction measurements at SAGE III wavelengths, Appl. Optics, 35, 3, 433-440, 1996.
Wang, Y. H., Liu, S. C., Wine, P. H., Davis, D. D., Sandholm, S. T., Atlas, E. L., Avery, M. A., Blake, D. R., Blake, N. J., Brune, W. H., Heikes, B. G., Sachse, G. W., Shetter, R. E., Singh, H. B., Talbot, R. W., Tan, D.: Factors controlling tropospheric O-3, $\mathrm{OH}, \mathrm{NO}_{\mathrm{x}}$ and $\mathrm{SO}_{2}$ over the tropical Pacific during PEM-Tropics B, J. Geophys. Res.-Atmos., 106, 32733-32747, 2001.

Wilson, J. C., Lee, S.-H., Reeves, J. M., Brock, C. A., Jonsson, H. H., Lafleur, B. G., Loewenstein, M., Podolske, J., Atlas, E., Boering, K., Toon, G., Fahey, D., Bui, T. P., Diskin, G., and Moore, F.: Steady-state aerosol distributions in the extra-tropical, lower stratosphere and the processes that maintain them, Atmos. Chem. Phys., 8, 6617-6626, doi:10.5194/acp-8-6617-2008, 2008.

$\mathrm{Yu}$, F.: Updated $\mathrm{H}_{2} \mathrm{SO}_{4}-\mathrm{H}_{2} \mathrm{O}$ binary homogeneous nucleation look-up tables, J. Geophys. Res., 113, D24201, doi:10.1029/2008JD010527, 2008.

$\mathrm{Yu}, \mathrm{F}$. : Ion-mediated nucleation in the atmosphere: Key controlling parameters, implications, and look-up table, J. Geophys. Res., 115, D03206, doi:10.1029/2009JD012630, 2010.

Yung, Y. L. and Demore, W. B.: Photochemistry of the stratosphere of Venus: Implications for atmospheric evolution, Icarus, 51, 199-247, 1982.

Yu, F. and Luo, G.: Simulation of particle size distribution with a global aerosol model: contribution of nucleation to aerosol and CCN number concentrations, Atmos. Chem. Phys., 9, 76917710, doi:10.5194/acp-9-7691-2009, 2009.

Yu, F. and Turco, R. P.: From molecular clusters to nanoparticles: The role of ambient ionization in tropospheric aerosol formation, J. Geophy. Res., 106, 4797-4814, 2001.

Yu, F. and Turco, R.: The size-dependent charge fraction of sub3-nm particles as a key diagnostic of competitive nucleation mechanisms under atmospheric conditions, Atmos. Chem. Phys. Discuss., 11, 11281-11309, doi:10.5194/acpd-11-11281-2011, 2011.

Yu, F., Luo, G., Bates, T. S., Anderson, B., Clarke, A., Kapustin, V., Yantosca, R. M., Wang, Y., and Wu, S.: Spatial distributions of particle number concentrations in the global troposphere: Simulations, observations, and implications for nucleation mechanisms, J. Geophys. Res., 115, D17205, doi:10.1029/2009JD013473, 2010.

Zhang, R., Suh, I., Zhao, J., Zhang, D., Fortner, E. C., Tie, X., Molina, L. T., and Molina, M. J.: Atmospheric new particle formation enhanced by organic acids, Science, 304, 1487-1490, 2004.

Zhao, J. and Turco, R. P.: Nucleation simulations in the wake of a jet aircraft in stratospheric flight, J. Aerosol Sci., 26, 779-795, 1995. 